EMERITA. Revista de Lingüística y Filología Clásica (EM)

LXXIII 2, julio-diciembre de 2005

pp. 263-302

ISSN 0013-6662

\title{
LA SINTAXIS DE LOS VERBOS “COMER" Y "BEBER” EN GRIEGO ANTIGUO. UN ESTUDIO SOBRE EL GENITIVO PARTITIVO
}

DANIEL RIAÑO RUFILANCHAS

Instituto de Filología, CSIC

\begin{abstract}
Las gramáticas del griego antiguo hablan de un régimen en genitivo para el objeto de los verbos de "comer" y "beber" que aparecería en alternancia con la marca de acusativo. Ello ofrece una dificultad para nuestra observación de que en griego antiguo la marca de acusativo aparece necesariamente cuando el referente del objeto directo es creado por la acción verbal, o resulta modificado por la misma. Nuestro estudio de la construcción de tales verbos muestra que la marca de genitivo es excepcional, y que con anterioridad al s. I d.C. sólo aparece, con un valor claramente partitivo, en contextos muy marcados.

Palabras-clave: sintaxis; acusativo; genitivo; partitivo; transitividad; griego antiguo; marca diferencial del objeto; caso gramatical; verbos de "comer"; verbos de "beber"
\end{abstract}

Our ancient Greek grammars take as a fact the existence of a genitive case marking for the direct object of the verbs expressing the idea of "eat" and "drink", alternating with the accusative. Such case behaviour is at odds with our observation that in ancient Greek the direct object whose referent is created or altered by the verbal action, is always constructed in accusative case. Our study of such construction shows that the genitive case is in fact very rare: before the first century AD it only appears, with a true partitive meaning, in a reduced set of clearly marked contexts.

Keywords: syntax; accusative; genitive; partitive; transitivity; ancient Greek; differential object marking; grammatical case; verbs of "eat"; verbs of "drink"

\section{PRESENTACIÓN Y PLANTEAMIENTO DE LA CUESTIÓN ${ }^{1}$}

No hay ningún estudio comprehensivo acerca del gen. partit. en griego antiguo, a pesar de que se trata de una construcción notable, y tipológica-

1 Emplearé las siguientes abreviaturas: ac.: acusativo; gen.: genitivo; dat.: dativo; Abs.: absoluto; partit.: partitivo; prep.: preposición, preposicional; CD: Complemento Directo; VAct, VMed., VPas.: Voz activa, media, pasiva; rel.: relativo. Para los autores y obras griegos sigo en general las abreviaturas del DGE. Para los menos conocidos usaré una cita más extensa. Además nótese: K.-A. = Kassel-Austin. Llamaré suplemento al complemento objetivo argumental no circunstancial y no pasivizable. 
mente muy poco común fuera de la familia indoeuropea ${ }^{2}$. Los ejemplos 1.b, 2 .b y 3 ilustran el uso partit. del gen. del que nos ocuparemos en este artículo.

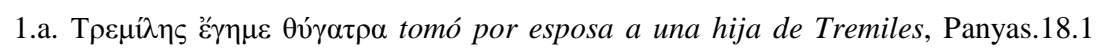
(Bernabé)

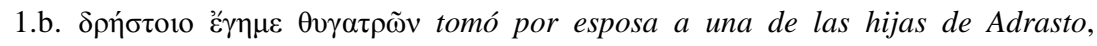
Il.14.121

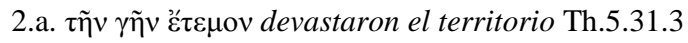

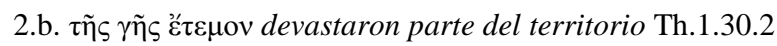

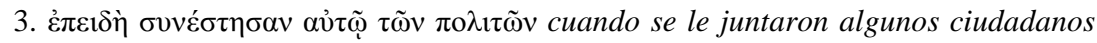
Hell.Oxy.13.5

Las gramáticas modernas describen el caso gramatical como la marca que codifica la función sintáctica de los elementos nominales respecto a su regente (cf. Blake 1994, p. 1). Sin embargo, la marca genitiva del "partitivo" no está señalando la función del nombre en ejemplos como los anteriores (donde puede ser un complemento directo, un suplemento o incluso un sujeto) sino que indica que la afectación de la acción recae sobre (o es ejercida por) una parte indeterminada del objeto (o del sujeto), lo que además nos informa acerca de la estructura semántica del nombre, pero resulta opaca respecto a su función sintáctica en la oración.

En este artículo me ocuparé únicamente del complemento de los verbos de "comer" y de "beber", que definiré con precisión más adelante. Como paso previo al estudio de la construcción partitiva dentro del griego en toda su extensión, creo que es de gran interés un detallado análisis de la sintaxis de los verbos de los que habitualmente se afirma reciben un complemento argumental con marca de gen. partit.: sólo el tratamiento crítico y pormenorizado de las diversas esferas en las que aparece esta construcción permitirá en un futuro abordar la cuestión del gen. partit. en toda su complejidad.

El problema principal que plantea la sintaxis de los verbos de "comer" y "beber" es que, a diferencia de otros verbos con los que sólo muy ocasionalmente se registra un gen. partit., se afirma a menudo que éstos reciben de manera regular un gen. Pero ¿por qué éstos, y no otros verbos, se construirían regularmente con un partit.? El tipo de afectación sobre el objeto directo que implican los verbos de "comer" y "beber" (el objeto resulta físicamente afectado) no nos haría esperar, en principio, una marca distinta a la de

2 Sí existen, sin embargo, interesantes estudios parciales al respecto, como el de Nachmanson 1942.

EMERITA (EM) LXXIII 2, julio-diciembre $2005 \quad$ pp. 263-302 ISSN 0013-6662 
ac. ${ }^{3}$ Por lo tanto surgen dos preguntas pertinentes que intentaremos abordar en este artículo: (a) Qué clase de gen. es éste que reciben los verbos de "comer" y "beber" y (b) Cuán frecuente es en realidad esta construcción con tales verbos. Confío además en que este artículo aporte también datos de interés sobre este grupo de verbos por sí. Los límites temporales de nuestro estudio se extienden desde Homero hasta el s. I d.C. ${ }^{4}$

\section{DOCTRINA TRADICIONAL Y MODERNA SOBRE LOS VERBOS DE “COMER”, "BEBER”}

Entre los gramáticos tardíos y escoliastas es frecuente la observación de que en ático los verbos de "comer" y "beber" rigen gen. Así lo afirma en el

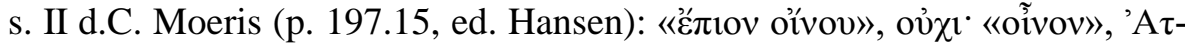

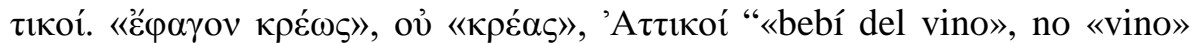
(sc. dicen) los áticos (i.e. los aticistas). «Comí de la carne», no «carne», los áticos". Más tarde, en el Philetaerus secc. 76.2, obra del ps. Herodiano (atribuida a Corneliano), leemos el mismo principio enunciado como una norma

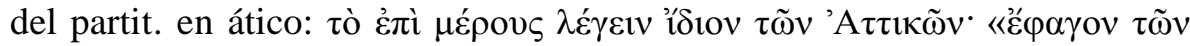

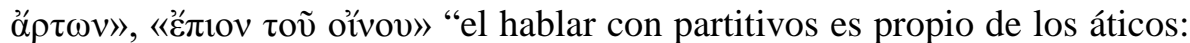
«comí de los panes», «bebí del vino»". De modo semejante en los escolios

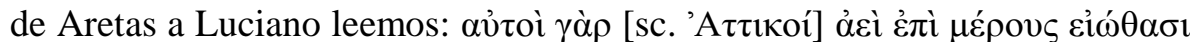

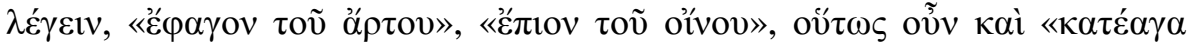

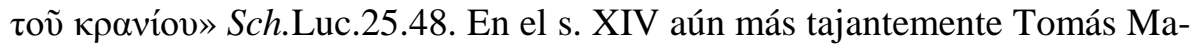
gíster eleva este principio a la categoría de regla Ecloga nominum et uerbo-

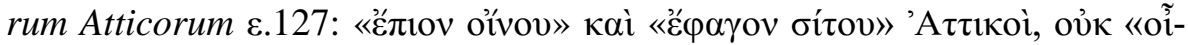

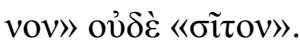

Cualquiera que lea estos testimonios no dejará de sorprenderse al saber que no hay ningún ejemplo (que yo conozca, al menos) de «oívov tíveıv»o

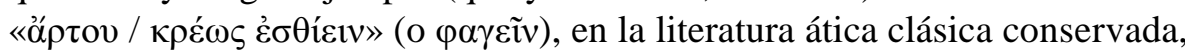
aunque la unión de tales verbos con los respectivos sustantivos en ac. (õ̃-

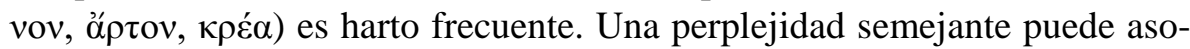

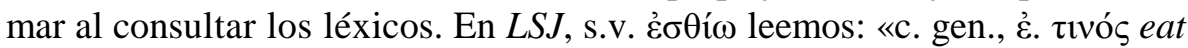

\footnotetext{
3 Al problema de la marca casual de los argumentos verbales está dedicada por entero mi tesis doctoral, Riaño 2004, donde se puede ver (§ III.16-18) cómo la marca de gen. del primer CD aparece siempre con complementos menos afectados que los de los verbos de "comer" y "beber".

4 Sólo ocasionalmente superaremos tales límites. Véase más adelante la lista de autores.
}

EMERITA (EM) LXXIII 2, julio-diciembre $2005 \quad$ pp. 263-302 ISSN 0013-6662 
of.., X.HG 3.3.6, etc.», pero a pesar de este «etc.» tal ejemplo parece ser el

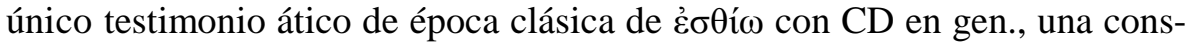
trucción poco habitual también fuera de tal dialecto.

A pesar de esta llamativa contradicción entre el principio enunciado por los gramáticos y una abundante cantidad de datos, las modernas gramáticas griegas parecen estar de acuerdo con los gramáticos antiguos y los léxicos en dos puntos al menos: (a) considerar la construcción de los verbos "comer", "beber" con gen. como característica de la prosa clásica, especialmente la ática, en oposición a la prosa de la koiné, y (b) considerar el régimen gen. de estos verbos como un ejemplo prototípico de gen. partit., aunque discrepen sobre el status sintáctico de este gen., la caracterización de la construcción y sobre la misma noción de gen. partit. Veamos primero algunos testimonios:

The same tendency to accus[ative] in Hell[enistic] Greek appears with verbs which (in

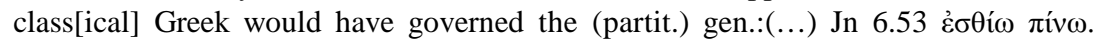
(Turner 1963, p. 244).

A classical author would have used the gen. more often where the acc. is found in the

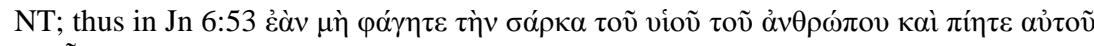

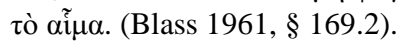

Wir sagen "Brot essen", der Grieche bestimmter "vom Brot essen" weil niemand alles Brot, was es in der Welt gibt, auf einmal zu verzehren imstande ist. Es handelt sich um folgende sich um folgende Kategorien (...) b) die Verba essen geniessen hungern,

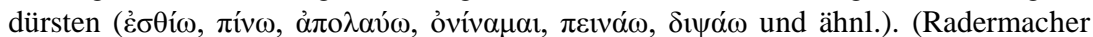
1911, p. 101) $)^{5}$.

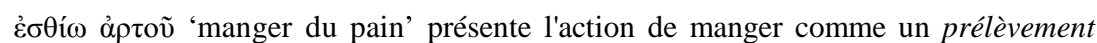
limité fait sur la matière indéterminée qu'est le pain consideréré comme aliment, et

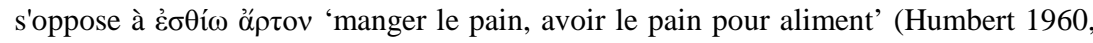
$\S \S 442-3)^{6}$.

Certains verbes admettent plus volontiers que d'autres le génitif partitif. Les verbes signifiant 'manger' et 'boire' (...) le génitif est choisi lorsque l'attention est attirée sur una certaine quantité de boisson ou de nourriture prise sur ce qui est offert. (Chantraine $1953, \S 62)$.

5 Esta doctrina remonta al menos hasta Tzetzes, quien intentando defender en Ari., $\mathrm{Nu}$.

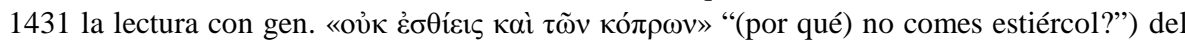
ms. M, frente a la lectura con ac. del resto de los manuscritos (aceptada por todos los edito-

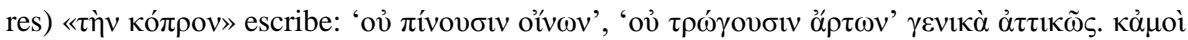

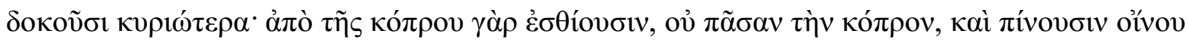

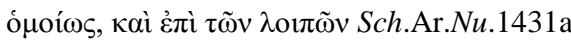

6 Semejantemente Delbrück 1893, p. 315; Basile 1998, p. 238, etc.

EMERITA (EM) LXXIII 2, julio-diciembre $2005 \quad$ pp. 263-302 ISSN 0013-6662 
Respecto a la caracterización de la construcción de gen. con estos verbos, tanto los tratadistas tardíos como los modernos vacilan entre la construcción con artículo y sin él, y como hemos visto no todos aclaran si esta construcción evoca la situación en la que un sujeto bebe parte del contenido de su copa en cierto momento; o si es aquella en que bebe el vino de su copa y no todo el vino que existe (como afirma Radermacher); i.a., o si es el vino a su disposición en cierto momento, $u$ otra de las varias interpretaciones partitivas que cabe imaginar.

En lo que se refiere a la a conceptualización de los verbos "comer", "beber", dentro del grupo de verbos que admiten un segundo argumento obligatorio en gen. hay muchas diferencias de un autor a otro. Humbert no considera que haya un tipo de verbos "comer" distinto de otros partitivos, mientras que Kühner-Gerth separan este grupo y aclaran el valor del caso:

Der Genetiv hat partitiven Sinn. Tritt also der partitive Sinn zurück oder ist er geradezu ausgeschlossen, so steht bei den Verben des Essens und Trinkens der Akkusativ, bei denen des Sättigens der instrumentale Dativ. So bei den Verben des Essens und Trinkens der Akk. ziemlich oft (vgl. des Weines u. Wein trinken, des Brotes u. Brot essen $\S 415,2$ ), wenn der Stoff schlechthin als Nahrungsmittel bezeichnet werden soll. (Kühner-Gerth 1898, § 417.2 Anm. 2).

En Schwyzer-Debrunner, el empleo de tales verbos con gen. sería un ejemplo del uso más directamente partit., listado tras los "puros" partits. «bei beliebigen Transitiva» y los verbos de "participar" Schwyzer-Debrunner 1950, pp. 102-3.

Como vemos, aunque la interpretación que hacen del partit. cambia mucho de unos autores a otros, parece unánime la opinión de que estos verbos se construyen habitualmente con un gen. partit., que es también la explicación más común para el complemento en gen. o gen. prep. con estos verbos frecuente en latín y en alguna lengua romance. Ante tal consenso no cabría esperar que los hechos fueran muy distintos de lo descrito, pero un estudio de los textos levanta serias dudas sobre la interpretación que suele darse a las siguientes cuestiones: (a) las condiciones en que puede darse el régimen en gen. y su alternancia con el ac; (b) la caracterización de tal caso como un gen. partit. en todas las ocasiones; (c) la explicación de este comportamiento, y su lugar en el sistema de casos griego; (d) la frecuencia del uso de ambos casos gramaticales y por tanto la adecuada caracterización de los verbos "comer", "beber" en los léxicos; (e) la oportunidad de incluir estos verbos en un grupo aparte, a la hora de tratar la sintaxis del gen.; (f) la existencia de 
diversos subgrupos de verbos dentro de "comer" y "beber", o si "comer" y "beber" pertenecen a la misma clase; (g) el aticismo de esta construcción.

\section{EL GENITIVO PARTITIVO EN LAS MODERNAS GRAMÁTICAS GRIEGAS}

\subsection{El concepto de "partitivo" en las gramáticas del griego}

"Partitivo" es un término que frecuentemente se emplea con no poca vaguedad en la literatura científica. En los gramáticos griegos y latinos y en la gramática tradicional occidental, el término "partitivo" o "construcción partitiva" designaba al menos tres cosas: (a) relación del nominal que designa el "todo" (el partit. subordinado) con el que designa la "parte" (el sintagma

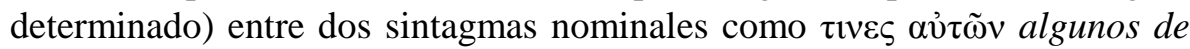
ellos ${ }^{7}$; (b-c) Dos tipos de construcciones adverbales en las que el objeto sólo resulta parcialmente afectado, entendiendo "parcial" en el mismo sentido que en las construcciones nominales, i.e., como un subconjunto del total. La primera de estas construcciones se da con verbos y lexías a los que llamare-

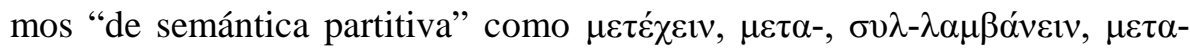

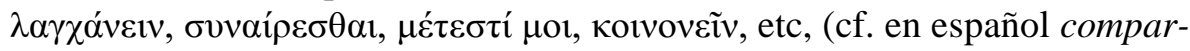

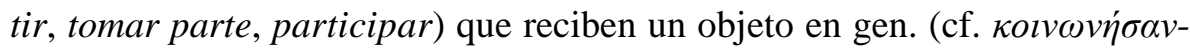
$\tau \alpha \varsigma$... $\tau \tilde{\omega} v \pi \rho \alpha \gamma \mu \alpha \dot{\tau} \omega v$ "tomando parte en los asuntos" Plb. I 6.7) ${ }^{8}$. El caso gen. de este objeto responde a mi juicio a su afectación parcial, y no resulta por tanto opaco respecto a su función sintáctica.

La segunda construcción adverbal partitiva es la que hemos ilustrado en los ejemplos 1-3, y en ellas el partit. es un objeto del verbo o incluso el sujeto, y la marca de gen. no informa sobre su función sintáctica. Las gramáticas afirman que este tipo de construcción partitiva puede darse con el objeto de cualquier tipo de verbo ${ }^{9}$, pero, salvo que alguien pueda aducir ejemplos en contra, debe reconocerse que los complementa effecta (es decir, aquellos que tienen por referente un objeto que se crea como resultado de la acción verbal) no aceptan nunca la marca de gen. partit. Ello es un índice, en mi opinión, de que el grado de afectación del objeto es relevante para la admisión de esta construcción.

$7 \quad$ Küh.-G., Gr.Gr. § 414.5. Cf. § 416 sobre la construcción adverbal.

8 Küh.-G., Gr.Gr. § 416.

9 Küh.-G., Gr.Gr. § 416 Anm. 2. Para una discusión razonada de este hecho, cf. mi tesis doctoral, § III.20.

EMERITA (EM) LXXIII 2, julio-diciembre $2005 \quad$ pp. 263-302 ISSN 0013-6662 
Fuera de la gramática tradicional, la etiqueta "partitivo" se ha extendido para indicar otro tipo de relaciones no totales o absolutas del elemento verbal con su objeto, como la que, en una teoría escalar de la transitividad, existe en las construcciones de transitividad reducida (v.gr. con un objeto no afectado) como la que se da con los verbos de percepción, de actividad mental, etc. Tal uso de la designación "partitivo" puede ser confuso si no se separa claramente del uso tradicional, aun reconociendo que se puede percibir entre los fenómenos que ambos designan una relación diacrónica y conceptual. Finalmente, "partitivo" indica el término subordinado de tales relaciones, que en griego puede venir marcado mediante el caso gen.

\subsection{Expresión de la idea partitiva en griego}

Resumiendo, para la expresión de la idea partitiva de un complemento verbal, el griego puede usar al menos cuatro recursos: a) un complemento en gen. (en época clásica casi siempre sin preposición); b) expresión léxica de tal idea partitiva en el SN, v.g. con un sustantivo que signifique cantidad limitada, como 'parte', 'trozo', 'algo' etc.; c) Uso de SN no determinado; d) Uso de un verbo que contenga en el lexema la idea partitiva.

$\mathrm{Al}$ igual que ocurre en español, la forma más frecuente de expresar una idea partitiva (en sentido amplio de "porción indefinida") con verbos "comer", "beber" es el uso del sintagma nominal no determinado como comple-

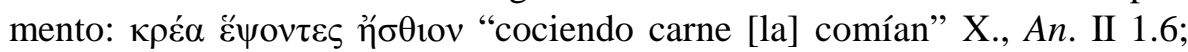

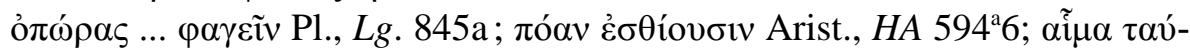

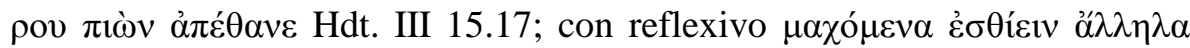
Pl., R. 589a. Éste, sin embargo, no es un procedimiento sin ambigüedades: En primer lugar, cuando el complemento indica un "contenedor" puede interpretarse como una medida del "contenido", y por tanto la interpretación

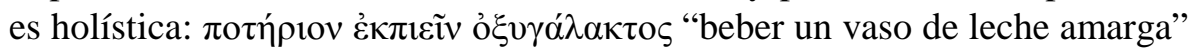
Plu., Art.3.2. Además, cuando la semántica del contexto lo permite, con el mismo sentido indeterminado se puede usar un sustantivo determinado con

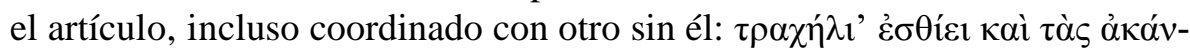
$\theta \alpha \varsigma$ "come desperdicios y las raspas (sc. del pescado)" Ar., Vesp. 968. El

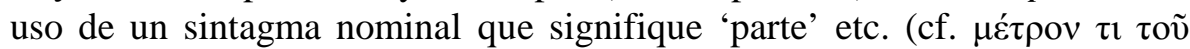

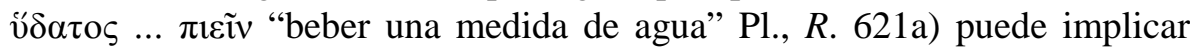
desventajas de economía lingüística ${ }^{10}$, y el uso de un verbo que incluya en

10 Este uso es más común para designar no una parte de un todo homogéneo, sino una EMERITA (EM) LXXIII 2, julio-diciembre $2005 \quad$ pp. 263-302 ISSN 0013-6662 
su definición la idea partitiva no es un recurso siempre disponible. Siendo así que la lengua puede emplear el complemento indeterminado en acusativo, o el complemento en gen. (determinado o indeterminado), cabe preguntarse qué es lo que hace posible o preferible la elección de la opción estadísticamente menos frecuente, i. e., la construcción de gen.

No hay estudios sobre la frecuencia de la construcción que ilustran los ejemplos $1 \mathrm{~b}, 2 \mathrm{~b}$ y 3 en griego, por lo que, para dar al lector una idea sobre la extensión de su uso emplearé los datos de un corpus que yo mismo analicé $^{11}$. En tal corpus la construcción aparece 14 veces en 100.000 palabras (es decir, una vez cada 7.140 palabras aproximadamente); cuatro de ellas con un $\mathrm{CD}$ que implica un cambio en el objeto, y las otras 10 con un $\mathrm{CD}$ que no implica tal cambio (no hay por tanto ningún ejemplo en función de sujeto). De los 5 autores del corpus, dos de ellos (Plb. y Vit.Aesop.G) nunca testimonian tal construcción en el muestrario por mí analizado. San Lucas, que emplea profusamente la construcción (6 ejemplos) sólo lo hace con prep., mientras que Th. y X. únicamente lo hacen sin prep.

\section{MARCA DE CASO Y GRADOS DE TRANSITIVIDAD}

No es éste el lugar para debatir en profundidad la clara relación que, en mi opinión, existe entre la marca de caso del objeto y el grado de transitividad. Resumiendo al máximo la hipótesis que al respecto he propuesto en otro lugar, la probabilidad de que un segundo argumento (objeto directo o suplemento) reciba la marca casual de gen. o dat. está relacionada estrechamente con el grado en que los hablantes consideren que el referente esté afectado por la acción verbal, de modo que cuanto menor sea la afectación, mayores son las probabilidades de que la marca del objeto no sea la del simple acusativo ${ }^{12}$. Propongo además que el grado de transitividad del verbo es relevante también para delimitar el grado de aceptabilidad de las construcciones partitivas puras, aunque quizás no haya una estricta relación proporcional inversa.

fracción de un conjunto formado por diversos elementos: $\alpha \rho ı \tau \tilde{\alpha} \nu \tau \imath \tau \tilde{\nu} \nu \pi \rho \sigma \gamma \varepsilon \gamma \rho \alpha \mu \mu \varepsilon ́ v \omega v$ desayunar algo de lo dicho Hp., Mul. 133.202.

11 Se trata de un corpus de 20.000 palabras de la obra de cada uno de los siguientes autores: Th., X., Plb., San Lucas (Evangelio y Act.Ap.) y Vit.Aesop.G. En total son 100.000 palabras, equivalentes a algo más de la mitad de la Historia de Heródoto. Cf. Riaño 2004.

12 Cf. nota 3 para un estudio muy detallado de la cuestión, donde discuto las posibles vías por las que pueden haberse extendido las marcas de gen. y dat.

EMERITA (EM) LXXIII 2, julio-diciembre 2005 pp. 263-302 ISSN 0013-6662 
Podemos resumir la relación entre grado de transitividad y marca de la construcción partitiva colocando mentalmente los ejemplos a lo largo de una línea imaginaria que representa el grado de afectación del objeto, de la siguiente manera: En un extremo están los uerba efficiendi puros, cuyos objetos (complementa effecta) siempre vienen marcados con el caso ac. y nunca pueden ser en griego partits. puros. Con este tipo de verbos, el sentido partit. requiere el uso de un indefinido, una construcción nominal partitiva, como

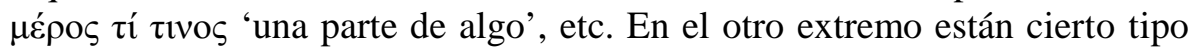
de verbos de transitividad reducida, los "verbos de semántica partitiva" que exigen una construcción partitiva en gen. El resto de los verbos cuyo sentido no sea incompatible con una interpretación partitiva admitirá ocasionalmente la construcción con gen. con restricciones impuestas, entre otros factores, por su grado de transitividad ${ }^{13}$. Según esta hipótesis, la frecuencia de aparición del tipo que ilustra el ejemplo 2.b, con un verbo que implica transformación del objeto, será residual, e inferior a la de otros grupos de verbos de transitividad reducida ${ }^{14}$. Si los verbos "comer", "beber" admiten habitualmente (o incluso exigen, como sugieren los gramáticos tardíos y algunos escoliastas) la construcción partitiva, estarían en una situación realmente excepcional, si, aceptando nuestra definición provisional para estos verbos (cf. § 5.1) se trata de verbos conceptualmente clasificados entre los que exigen la transformación del objeto (i.e., el nivel más alto de afectación del objeto tras los verbos que implican "creación" del objeto), y habrá que modificar la definición, o explicar la anomalía dentro de la teoría, so pena de tener que rechazar la hipótesis que extiende la pertinencia del grado de afectación del objeto también a la asignación de la marca del partit.

\subsection{Principios de método}

\section{Metodología DE LA INVESTIGACióN}

Parto de la base de que, a la hora de describir cómo se conceptualiza en forma lingüística una acción que se sitúa en el entorno físico de los hablan-

13 Hay otras consideraciones en las que no podemos profundizar aquí. En español, por ejemplo, es frecuente con algunos verbos de transitividad elevada una construcción holística cuando el contexto exige una interpretación partitiva, que sería el reverso de la situación que estudiamos. A modo de ilustración, con quemar se admite "el fuego quemó el bosque" cuando la situación exige interpretar que tan sólo una parte del bosque fue quemada.

14 Esta hipótesis parece avalada por el repertorio de tales construcciones que puede consultarse en Küh.-G. Gr.Gr. § 416 Anm. 2, que es el más extenso que conozco. Otro ejemplo es Hom., Od. XV 98, con ỏ $\tau \tau \alpha$ ' 'cocer'.

EMERITA (EM) LXXIII 2, julio-diciembre $2005 \quad$ pp. 263-302 ISSN 0013-6662 
tes, debe considerarse en primer lugar la descripción de los sucesos externos observables, aunque ésta por sí no sea suficiente. Si ponemos aparte la experimentación con hablantes en el laboratorio (lo que naturalmente nos está vedado para el griego antiguo), el estudio detallado de los usos lingüísticos es casi lo único que nos permite conocer cuáles de tales fenómenos externos son conceptuados lingüísticamente, un proceso en el que necesariamente se dejan de lado un gran número de fenómenos concomitantes.

Metodológicamente, sin embargo, antes de comenzar el trabajo de investigación es preciso partir de una definición obtenida del estudio del material más inmediatamente disponible, para delimitar la recogida de datos. Para echar a andar, y como definición provisional, he comenzado por dar una definición de cada uno de los tipos de verbos de los que me ocuparé en este artículo. Emplearé "comer" para designar la acción por la que un sujeto animado hace que una sustancia sólida externa pase a través de la boca a su estómago. Verbos "comer" son aquellos en cualquier lengua que designan esta función. Empleo "beber" cuando tal sustancia externa es líquida. Típicamente, la acción será consciente y la sustancia constituirá un alimento, i.e. una sustancia apta para mantener el organismo en funcionamiento y para saciar una sensación natural e inconsciente de los seres vivos.

Tal definición, como se ve, está basada en ciertos hechos físicos observables que tienen lugar cuando un ser vivo realiza la acción que conceptualizamos como "comer", "beber", pero no agota desde luego todos estos hechos. A mi juicio, como he dicho, no es ocioso partir de los datos de la realidad extralingüística, con tal de que se entienda que siempre pueden desbordar el concepto lingüístico, pero en un segundo estadio es imprescindible observar la extensión de los items léxicos para determinar cuáles de tales hechos no forman parte del concepto lingüístico. Cierto tipo de movimientos de las articulaciones motoras de un vertebrado son una condición indispensable para que pueda darse la acción de "correr", pero resultaría ocioso incluir la descripción de tales movimientos en una definición léxica de "correr" desde el momento en que observamos que el verbo "correr" se emplea igualmente con un agente no dotado de extremidades, e incluso no animado. La definición léxica de "correr" en español, por tanto, implicará el desplazamiento a una velocidad superior a la que ordinariamente se conceptúa para la clase de agente que la ejecuta, pero no incorporará, entre otras cosas, una referencia al funcionamiento del sistema locomotor de éste. De igual manera, en la definición de "comer", "beber" resultan ociosas precisiones sobre el movi- 
miento del órgano que recibe la comida, los procesos enzimáticos subsiguientes, etc. Al final del trabajo veremos de qué forma debe ser precisada la definición (en ciertos contextos) para dar cuenta de los hechos sintácticos observados en griego.

\subsection{Formación de un corpus de estudio}

He intentado que la búsqueda de material fuera lo más completa posible, pero dado que no podía pretender abarcar todos los textos, he optado por combinar una búsqueda intensiva dentro de un corpus amplio, pero limitado, de autores griegos (Corpus de "comer" y "beber", en adelante $C C B$ ), con el cotejo de los datos de los principales diccionarios generales. En una primera fase del trabajo busqué todos los verbos griegos para "comer", "beber", y recogí sistemáticamente la información que sobre ellos dan los principales léxicos griegos, especialmente el régimen, rasgos semánticos secundarios, clase de sujeto, género literario y fecha del autor. En la segunda fase de elaboración establecí un repertorio de autores $(C C B)$ que se extendiera desde Homero hasta el siglo I d.C., lo suficientemente representativo de los distintos estilos literarios y niveles de lengua, con las limitaciones que imponen la escasez de testimonios. (Los novelistas del s. II d.C. y Hld., con el que entramos en el s. III d.C. se incluyen sólo para no eliminar buena parte del corpus de los novelistas, que tiene un completo léxico propio.) El total de los verbos "comer", "beber" estudiados es de 152, y el número de pasajes considerados se acerca a los $5.000{ }^{15}$.

La lista de autores del $C C B$ es la siguiente: Hom., Hes., A., Hdt., S., E., Antipho, Th., Hp., Ar., X., Pl., Aesch., D., Arist., Men., Herod., Plb., NT, Ant.Diog., Plu.; (Scriptores erotici del s. II:) Iambl., Lollian., Ach.Tat., X.Eph., Charito, Longus, Hld. (III d.C.); Vit.Aesop.G (I-II d.C.)

15 El número de citas provenientes de $C C B$ son 4.112, que se reparten así según el caso del primer complemento: con ac.:2.230 (53\%); Abs.:1.469 (35\%); con todo tipo de gen.:170 (4'1\%); con Prep. + gen.:58; en V.Pas.:171; Sin contexto:14; Los datos del Corpus Hippocra-

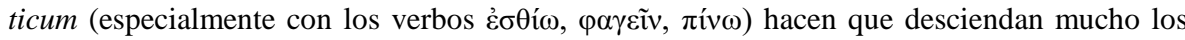
porcentajes generales de usos absolutos, que sin este corpus serían mayoría. He considerado 948 citas procedentes de los dos principales léxicos, repartidas así: de DGE 313; de LSJ 635. Sumando ambas fuentes tenemos 5.060 pasajes. Téngase en cuenta, sin embargo, que algunas decenas pasajes de CCB se repiten en los léxicos.

EMERITA (EM) LXXIII 2, julio-diciembre $2005 \quad$ pp. 263-302 ISSN 0013-6662 


\subsection{Nota sobre los léxicos, concordancias y ediciones usadas}

Los léxicos generales consultados han sido el de Bally, ThLGr y sobre todo $D G E$ y $L S J$. Sigo preferentemente al $D G E$ frente a $L S J$ hasta $\dot{\varepsilon} \kappa \pi \varepsilon \lambda \varepsilon-$ $\kappa \alpha ́ \omega$, y a éste frente a los dos primeros para el resto del léxico ${ }^{16}$. Cuando discrepo de sus interpretaciones lo hago constar.

El léxico del epos antiguo está excelentemente tratado hasta ópó $\omega$ en LFrGE. Igualmente hay buenos léxicos completos para Hdt., S., A., Th., NT y los novelistas; para Plb. hasta ómicron, y hay unos excelentes índices de Hp. Las ediciones usadas para tales autores son las que siguen tales obras. Para el resto de los autores hemos debido utilizar los textos del TLG, (usando el programa informático Pandora 3), por distintas razones: los léxicos de E., Ar., D., Aeschin., Men., Vit.Aesop.G sólo contienen las formas (no los lemas) y no son especialmente útiles para la sintaxis; Los de Pl., Arist., Plu., $\mathrm{X}$. son incompletos. El de X. está especialmente anticuado y ha sido reemplazado por una pléyade de léxicos parciales, algunos valiosos, pero en general casi por completo inútiles para un trabajo sobre sintaxis. Peor es la situación de la obra de Galeno, para el que no existe una concordancia ni un léxico propiamente dicho, razón por la cual hemos prescindido de él. Debido a esta falta de léxicos útiles para una investigación sintáctica en muchos autores he renunciado a buscar en $C C B$ aquellos verbos que sólo ocasional o marginalmente presentan el sentido "comer", "beber".

No aspiro a haber reunido una lista completa de los verbos "comer" y "beber", y soy consciente de que el elenco de tales verbos puede aumentarse quizás en algunas decenas de formas más o menos raras y dialectalismos, escudriñando los textos, léxicos y glosarios, pero creo que el repertorio que presento es desde un punto de vista estadístico suficientemente representativo, y desde luego incluye los verbos más comunes para cualquier dialecto del período estudiado.

\section{REPERTORIO DE LOS VERBOS “COMER”, “BEBER”}

Al final de esta lista se incluyen algunos verbos que no son propiamente (o no en todas las épocas) "comer", "beber", pero que están próximos a

\footnotetext{
16 Además de ofrecer mayor documentación, abarcar un periodo más amplio, seguir ediciones mejores y, en general, presentar una mejor disposición de los artículos, DGE (seis volúmenes hasta la fecha, de $\alpha_{-}$- hasta $\left.\dot{\varepsilon} \kappa \pi \varepsilon \lambda \varepsilon \kappa \alpha ́ \omega\right)$ especifica el régimen del verbo, algo que $L S J$ omite a menudo (cf. $\lambda \varepsilon^{i} \chi \omega$, etc.).
}

EMERITA (EM) LXXIII 2, julio-diciembre $2005 \quad$ pp. 263-302 ISSN 0013-6662 
ellos. Son, especialmente los verbos de "probar" o "masticar", ninguno de los cuales incluye la acción de ingerir, pero que contextualmente pueden ser interpretados como tales.

Varios datos que inmediatamente saltan a la vista advierten que "comer", "beber" no son verbos de una semántica sencilla. En primer lugar, destaca el supletismo de los principales verbos que se emplean para la noción "comer" en la mayoría de los dialectos (aunque el detalle cambia de uno a otro). Con gran frecuencia estos verbos presentan una oposición de voces con la alternancia de sentido VAct.= alimentar (criar, hacer pastar), siempre con complemento en ac./ VMed.= "comer", con complemento en ac. o en gen. Otros ofrecen una forma med. con el sentido "comer" y una act. con el sentido "preparar la comida" o "invitar a comer", etc., mientras otros sólo tienen una forma activa con su correspondiente pasiva. Abundan los usos abs., no sólo en los casos donde ello es más esperable (bien porque el complemento ha sido aglutinado en la forma verbal, bien porque se ha incorporado a la semán-

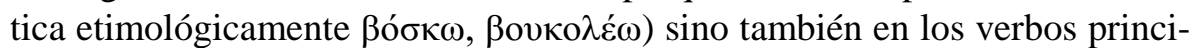

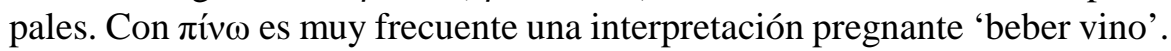

El comentario a los pasajes que ejemplifican la constr. con objeto en gen. durante el periodo estudiado lo doy en $\$ 7$. Entre paréntesis aparecen los verbos sólo testimoniados en glosarios, léxicos y escolios, sin que nos conste su constr. antigua, y que por tanto no entran en nuestro estudio; Entre corchetes aparecen los que solo he encontrado testimoniados como usos figurados marginales. No he buscado en $C C B$ aquellos verbos en los que el sentido edere, bibere es secundario o marginal, pero sí doy los datos de los léxicos. Todos los léxicos modernos incluyen entradas separadas para غ̇ $\sigma \theta i ́ \omega$ / '̌́ $\sigma \theta \omega$, ра́ $\gamma \omega$ y $\check{\varepsilon} \delta \omega$, pero los compuestos siempre se lematizan bajo la forma del correspondiente derivado de $\dot{\varepsilon} \sigma \theta i ́ \omega$, al que remiten las otras entradas. Aunque en algunos casos esto puede ser objetable, especialmente atendiendo a criterios cronológicos, hemos respetado esta convención.

1: Principales verbos para "comer", "beber", y sus compuestos: (A) “comer": $\beta 1$ -

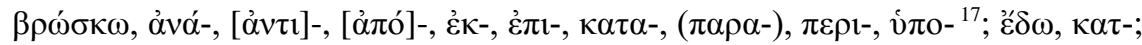

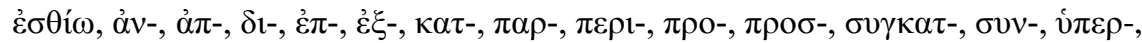
(ن்

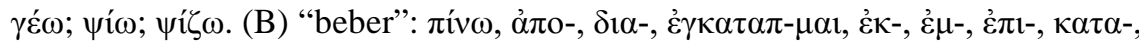

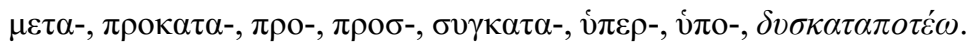

17 Erróneamente lematizado en v. med. por $L S J$.

EMERITA (EM) LXXIII 2, julio-diciembre $2005 \quad$ pp. 263-302 ISSN 0013-6662 
2: Intensivos (no incluidos en otra clasificación): $\gamma \rho \alpha \dot{\omega} \omega,(\gamma \rho \alpha i v \omega)$; $\delta \alpha \dot{\tau} \tau \omega, \kappa \alpha \tau \alpha-$;

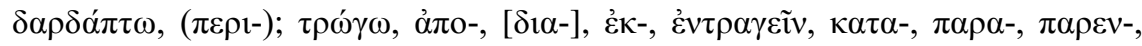

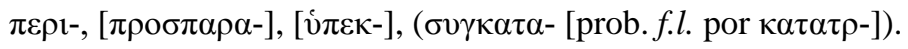

3: Derivados de (a) el nombre de una comida del día; (b) el nombre de un alimento, o de la palabra para "alimento"; (c) otros: (A) $\dot{\alpha} \rho 1 \sigma \tau \alpha \dot{\alpha} \omega, \dot{\alpha} v-,(\dot{\alpha} \pi-),[\delta 1 \alpha-\mu \alpha 1], \dot{\varepsilon} v-$,

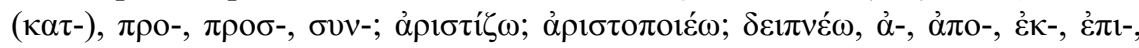

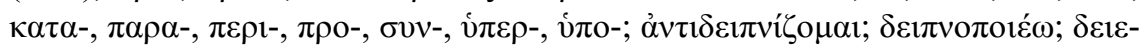

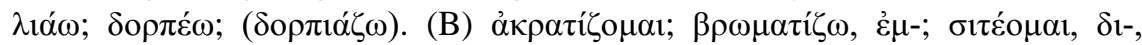

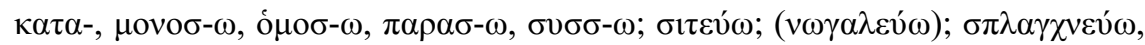

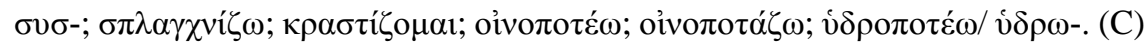
$\pi \alpha \rho \alpha \theta \varepsilon \rho i \zeta \omega$.

4 Extensiones metafóricas o metonímicas de las operaciones relacionadas con el

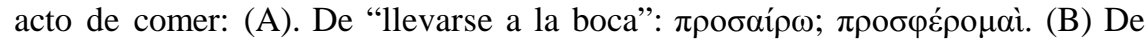

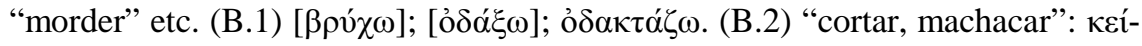
$\rho \omega ; \pi \alpha i \omega ;[\sigma \pi \mathrm{o} \delta \varepsilon \dot{\varepsilon} \omega] ; \varphi \lambda \alpha \alpha ́ \omega$. (B.3) "masticar": $\chi v \alpha v ́ \omega ; \pi \alpha \rho \alpha \chi v \alpha v ́ \omega$. (B.4) "gastar

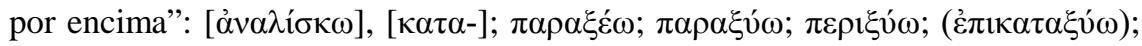

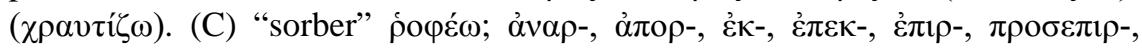

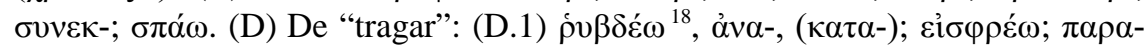

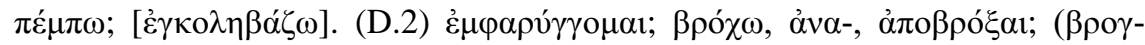

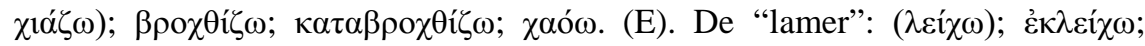

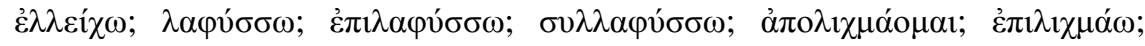

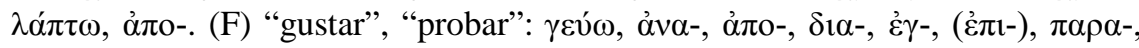

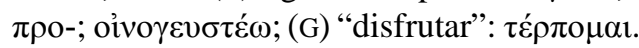

5. Extensiones metonímicas de las operaciones de "tomar" o "repartir" la comida:

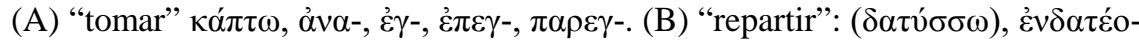

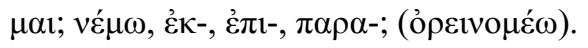

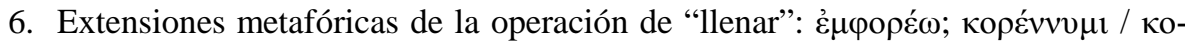

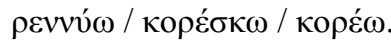

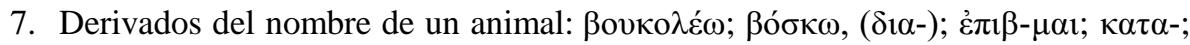

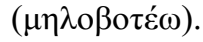

\section{RESUMEN DE LOS USOS DE LOS VERBOS “COMER”, “BEBER”}

Para cada verbo, doy el nombre del corpus del que proceden los ejemplos (DGE, LSJ, CCB, etc.), seguido entre paréntesis del número total de ejemplos contabilizados, repartidos luego según el caso gramatical de la cons-

$18 L S J$ lematiza poıßßé $\omega$, pero cf. Chantraine, 1953, s.v. acerca de la falsa grafía. -ot-.

EMERITA (EM) LXXIII 2, julio-diciembre 2005 pp. 263-302 ISSN 0013-6662 
trucción. Un asterisco entre paréntesis indica que el $C C B$ no añade ninguna cita nueva a la información de los léxicos; dos asteriscos indican que el verbo no está testimoniado en $C C B$; y tres asteriscos, que el sentido "comer", "beber" es secundario o marginal, y no ha sido buscado en $C C B$.

\subsection{Principales verbos simples usados para "comer", "beber" 19}

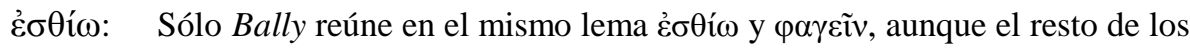
léxicos sí tratan conjuntamente los compuestos de ambos verbos. $L S J$ da 15 citas con el sentido estricto "comer" (más otras en usos figurados o metafóricos), de las cuales abs.:4, ac.:8, gen.:1; VPas.:2. Los redactores de $L S J$ parecen mostrarse esperanzados de encontrar nuevos usos comparables con gen. en el futuro, por-

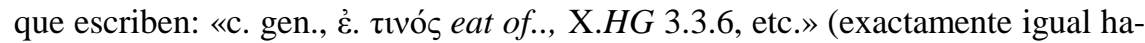
ce Bally); $C C B$ (578): ac.:356; gen.:12; prep.:8; VPas.:36; abs.:166. De las construcciones con gen. 2 son reflexivos, 2 rels. y 1 comparativo. Arist., Fr. 281 es cita de Aelian., y su sintaxis. Los 6 nuevos casos relevantes de construcciones con gen. en $C C B$ son: Plu., Brut. 47.3 .5 (Grupo A.3), Longus III 8.2 (Grupo B), Hp., Nat.Mul.45, 93, 59, Mul.107 (Grupo D).

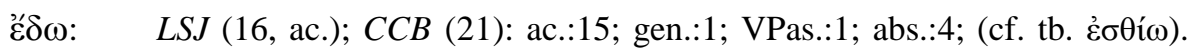
Los léxicos modernos (Bally, $L S J)$ sólo recogen la construcción con ac., pero en $C C B$ aparece con gen. en Ar.Nu.121 (Grupo F), ya citado (¡2 veces!) en $T h L G r$ s.v.

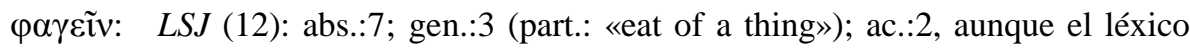
advierte de que el uso con ac. es más frecuente; $C C B$ (378): ac.:220; gen.:27; prep.+ gen.:6; abs.:125. LSJ trae otros dos ejemplos para ejemplificar el sentido "eat up" que corresponden a los usos abs. y ac. respectivamente. Bally trata juntamente este verbo con $\dot{\varepsilon} \sigma \theta i ́ \omega$, pero se olvida de ejemplificar los usos de aquél

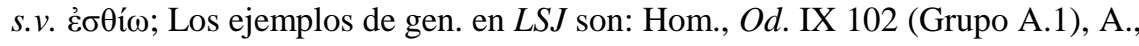
Supp. 226 (Grupo A.2) y Hom., Od. XV 373 (Grupo F). De los ejemplos en gen. de $C C B$, tres son los ya citados por $L S J$; Hom., Od. IX 232, Hp., VM 8, Plu.,

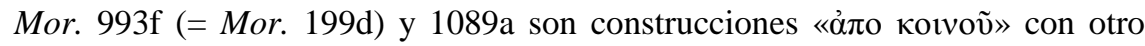
sintagma que exige gen.; Pl., $L g .845^{c}$ es gen. de lugar; Plu., Mor. 286c y Plu., Rom. 9.6.10 son cita literal de A., Supp. 226; Por otro lado Arist., Mir.831227, 844 32, Plu., Mor. 991e, 974b son todas ellas paráfrasis de Arist., HA 612 24 (cf. sin embargo Plu., Mor. 918c). Tenemos por tanto los siguientes nuevos

19 De los verbos que he buscado en $C C B$, presentan también más de 30 citas $\kappa \alpha \tau \varepsilon \sigma \theta i ́ \omega$

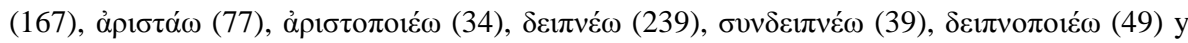

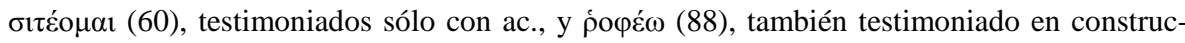
ción con gen.

EMERITA (EM) LXXIII 2, julio-diciembre $2005 \quad$ pp. 263-302 ISSN 0013-6662 
ejemplos de construcción con gen.: Arist., HA 612 24 y sus paráfrasis (Grupo A.1); E., Fr. 82.38, Ar., Eq.1181, Arist., EN 1149a14, Plu., Mor. 991a (Grupo A.2); Plu., Mor. 371d (Grupo A.4); Arist., Mir. 845a 30, Fr. 343.22 (listados en el apéndice de § 10) son ejemplos tardíos de Grupo A; Hp., Acut.(Sp.) 18 (Grupo B.2); Hp., Epid. IV 41 (Grupo D). Si hubiera que contar X., An. IV 8.20, sería

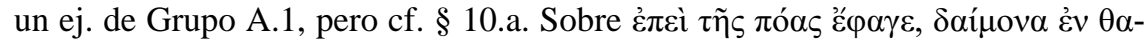

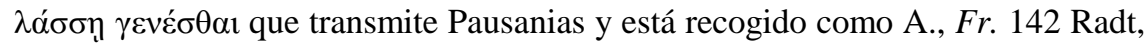
no nos consta cuáles eran los ipsissima uerba del poeta (sería un ejemplo de Grupo A).

$\beta \imath \beta \rho \omega ́ \sigma \kappa \omega$ : Etimológicamente $\beta \imath \beta \rho \omega ́ \sigma \kappa \omega$ procede de una raíz que significa 'tragar', pero en griego es un verbo "comer" intensivo. DGE (16): ac.:4; VPas.:2, gen.:4 y abs.:6, a los que generosamente añade otros 13 ejemplos en VPas. De

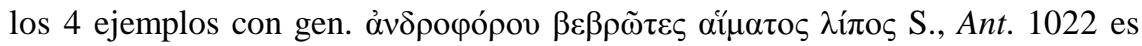
obviamente una errata (debería añadirse a los ejs. con ac). Tenemos por tanto 3 ejemplos relevantes de construcción con gen. testimoniados en los léxicos: Hom., Od. XXII 403, Theoc. 25.224 (Grupo J) y Ar., V. 462 (que examinaremos en Grupo A.2), a los que $D G E, L S J$ y Bally dan una interpretación explícitamente partitiva («[manger] une part de qqe ch., manger avidement de qqe. ch.»); $C C B$ (41): ac.:16; gen.:2 (ya citados por $D G E$ ); VPas.:10; abs.:13.

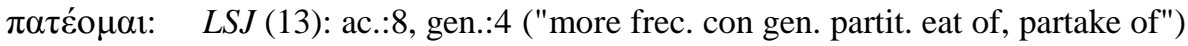
y abs.:1, del que dice es una construcción rara. $L S J$ afirma que la única cons-

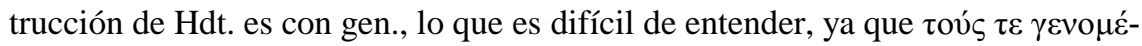

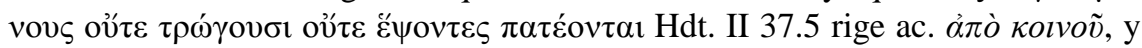

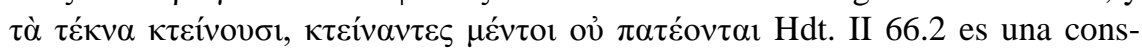

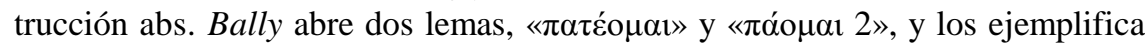
con una clara inflación de gens.: por un lado cita en ambos artículos Hom., Od.

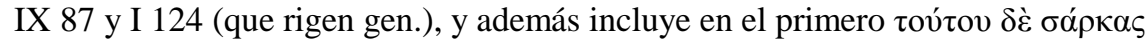

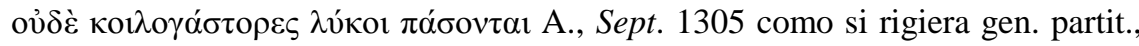

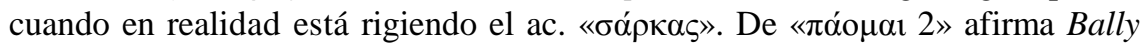

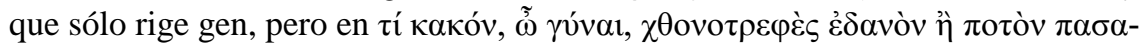

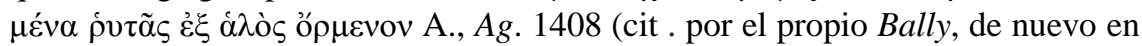
ambos lemas) gobierna los dos ac.; $C C B$ (31): ac.:14; gen.:13; abs.:4. Este verbo presenta, con diferencia, la proporción más grande de usos en gen. entre los verbos propiamente "comer", "beber": S., Ant. 202, Hdt. II 37.4, I 73.6, II 47.2, Plu., Mor. 998 (cita de Arato) (y Hom., Od. IX 93) son ejemplos de Grupo A. El resto, i.e. Hom., Il. XIX 160, XXIV 641, Od. I 124, IV 61, IX 87, X 58, 384 forman el Grupo C.

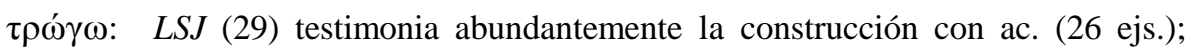
abs.: 2; VPas.: 1; $C C B$ (53): ac.: 45; gen.: 1; VPas.: 1; abs.: 6. Men., Fr. 83.2 (K.-A.), no recogido en los léxicos, es el único testimonio que he encontrado de

EMERITA (EM) LXXIII 2, julio-diciembre 2005 pp. 263-302 ISSN 0013-6662 
la construcción con gen. (cf. Grupo M).

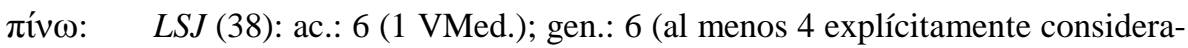
dos partit.); prep.+ gen.: 10; abs.: 15; CCB (1804): ac.: 1018; gen.: 62; prep.+ gen.: 52; VPas.: 57; abs.: 611; Sin contexto: $4^{20}$. De los ejemplos citados por LSJ, Hom., Il. VIII 232, y IV 346 son en realidad una construcción de ac. del que depende un gen. adnominal; Thgn. 962 es un gen. de origen. De las construcciones relevantes con gen. de LSJ, Hom., Od. XV 373 pertenece a nuestro Grupo F, y $O d$. IV 220, XI 96 a Grupo A. Sólo Od. XXII 11 pertenece al tipo IV.J de objetos en gen. partit.; de los 62 casos de construcción con gen. en $C C B$, 3 aparecen ya en $L S J$; 12 son gen. de origen (Hom., Od. XIX 62, Hdt. I 188.1, E., Cyc. 530, Arist., HA 626 27 , SE 178 34 , IEp.Cor.10.4, Plu., Pomp. 73.2, Mor. 381D, Ach.Tat. IV 18.3, Longus I 20.3, IV 26.4, Plb., Fr. 73 [prob. la sintaxis de Ateneo]); 4 son rel. (Hdt. IV 2.1, 66.1, Plu., Mor. 199d, 1089a); Pl., $R$. 621 b es una construcción «ảંò кoเvoṽ» y Men., Fr. 737.1 (K.-A.) es otro tipo de construcción (cf. Apéndice-c). Las 42 nuevas construcciones relevantes (de las cuales 4 están repetidas) y el grupo al que pertenecen son: Grupo A.1: Ach.Tat. III 4.4; Grupo A.2: E., Alc. 845, Pl., Lg. 647e, Pl., Lg. 649a, Plu., Lyc. 9.5, (Ps.)Plu., Fr.10, 454e y 624a, 740e; Grupo B: Hp., Int. 39, Vet.Med. 13; Grupo C: (Ps.)Plu., Fr. 30, 655 ${ }^{\mathrm{f}}$, Longus 2.36; Grupo D: Hp., Acut.(Sp.) 38, 93, Int. 21, 26, 42, 44, Morb. 2.47, 52, 7.1, Mul. 23, 203, 78, Nat.Mul. 32 líneas 59, 91 y 96 (Littré), 60 (= 35), 109, 132, Steril.35 (= 137), 224, 217 (= Superf. 29), Superf. 29 lín. 38 (Littré); Grupo K: Hp., Remed.56, Hp., Nat.Mul.81.

\subsection{Verbos no testimoniados en construcción con complemento en gen.} (111 verbos)

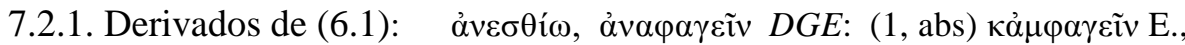

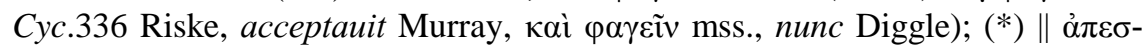

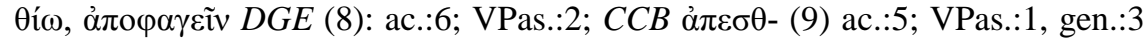

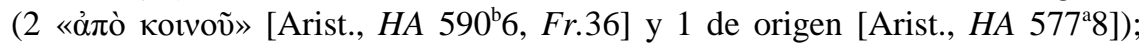
$\dot{\alpha} \pi \circ \varphi-; C C B(3$, ac.) (cf. $\varphi \alpha \gamma \varepsilon \tilde{v} v$ para un caso debatido) $\| \delta \imath \varepsilon \sigma \theta i ́ \omega, \delta 1 \alpha \varphi \alpha ́ \gamma \omega D G E$ :

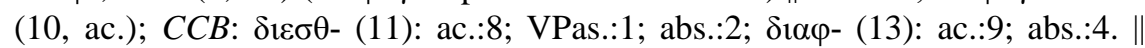

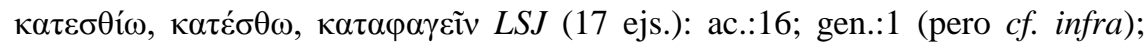

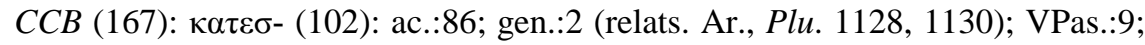
abs.:5. $\alpha \alpha \alpha \varphi-(65)$ ac.:56; abs.:7; sin contexto:2. Según $L S J$ hay un ejemplo de gen. partit. en en Amips. 6 (cómico ateniense de IV-III), pero resulta ser una ma-

20 Un buen número de construcciones c. ac. son construcciones ảjò кoเvoṽ del tipo $\tau \alpha \tilde{v}$ -

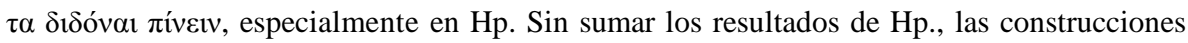
absolutas son más numerosas que las de ac., sumando casi un $50 \%$ de todas las construcciones de $\pi \dot{v} \omega$.

EMERITA (EM) LXXIII 2, julio-diciembre $2005 \quad$ pp. 263-302 ISSN 0013-6662 
la interpretación de Meinecke (seguida por los editores del diccionario, aunque ya fue corregida por Edmonds, p. 200 y luego por K.-A.) al haber tomado el título de una comedia por el verbo que rige el gen. (que en realidad depende de $\left.\delta \varepsilon \omega^{21}\right)^{21}$. Fuera del pasaje, en este autor sólo aparece el verbo en construcción ab-

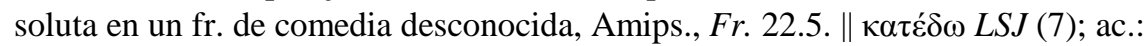

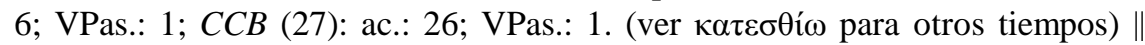
$\pi \varepsilon \rho \iota \varepsilon \sigma \theta i ́ \omega, \pi \varepsilon \rho \iota \varphi \alpha \gamma \varepsilon \tilde{v} \operatorname{LSJ}(3$, ac.) (1er. testimonio en Luc.); (**) \| $\pi \rho \circ \varepsilon \sigma \theta i ́ \omega$,

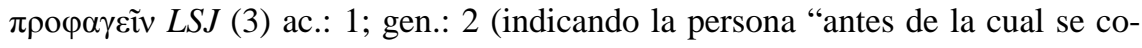
me"); $C C B: \pi \rho о \varepsilon \sigma-(2):$ ac.: 1; VPas.: 1; $\pi \rho о \varphi-$ ac.: $1 . \| \pi \rho о \sigma \varphi \alpha \gamma \varepsilon i ̃$ LSJ: (1,

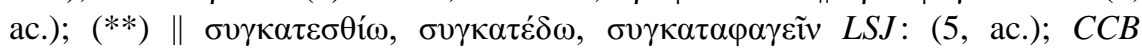

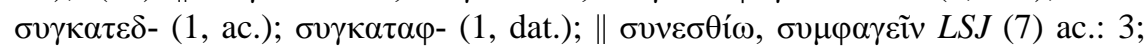
dat.: 3; prep.+ gen.: $2 \|$ vं $\pi \varepsilon \rho \varepsilon \sigma \theta i ́ \omega, L S J:(1$, abs.); (*).

7.2.2. Intensivos: $\gamma \rho \alpha ́ \omega D G E$ testimonia 3 apariciones. de interpretación no segu-

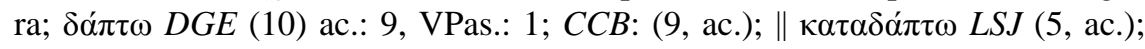
$C C B$ (3, ac.) $\| \delta \alpha \rho \delta \alpha \dot{\pi} \tau \omega D G E$ (16): ac.: 10; VPas. 6; CCB (6, ac.) $\| \pi \alpha \rho \varepsilon v-$ $\tau \rho \omega ́ \gamma \omega ~ L S J:(1$, VPas.) $\| \pi \varepsilon \rho \imath \rho \omega ́ \gamma \omega L S J:(5$, ac.); $C C B$ (3, ac.) $\| \dot{\varepsilon} \kappa \beta ı \rho \omega ́ \sigma \kappa \omega$,

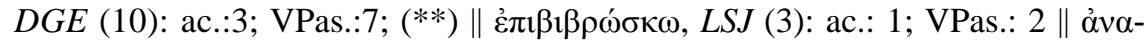

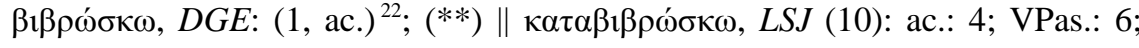

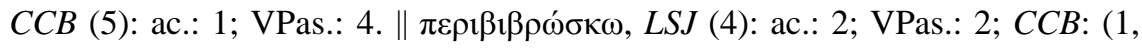

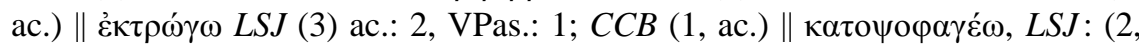
abs.); (**) $\| \dot{\alpha} \pi$ o $\operatorname{li}^{\prime} \omega \omega, D G E$ (4): abs.: 3; ac.: 1; $C C B$ (2): ac.: 1; abs.: 1. \| $\delta 1 \alpha-$

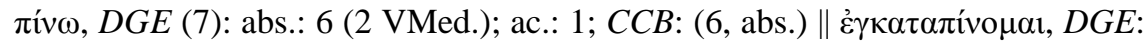

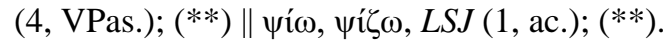

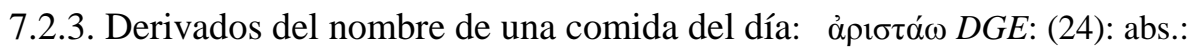

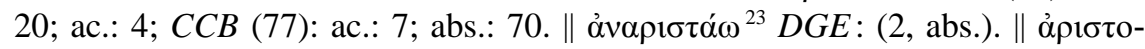
$\pi$ olé $\omega$ DGE (15, abs. con el sentido “comer") ${ }^{24}$; $C C B$ (34): VPas.: 1; abs.: 33. ॥

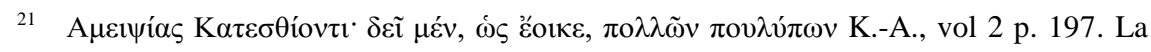
fuente es Ath.100.

22 Errata del $D G E$ que traduce «morder», pero bien en $L S J$, Bally que traducen "devorar".

23 Hay un curioso error en los modernos léxicos griegos, llamativo por lo obstinado:

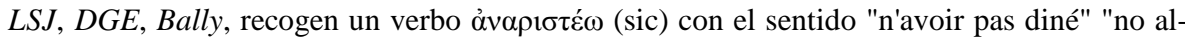

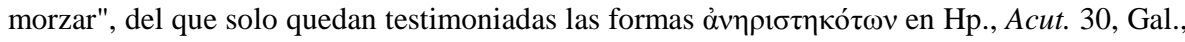
Consuet. p.13.14. Que se lo haya incluido en la conjugación en-غ́c se debe probablemente a

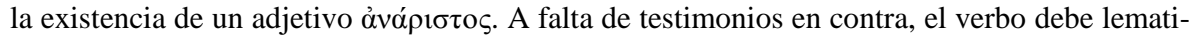

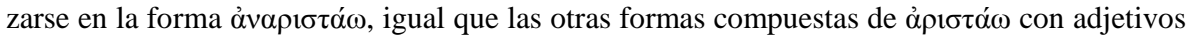

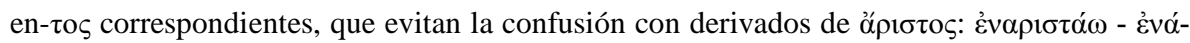

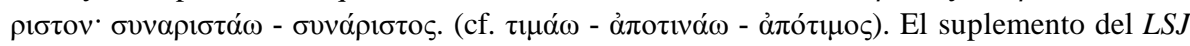
ha corregido su entrada conforme al $D G E$, sin corregir el lema.

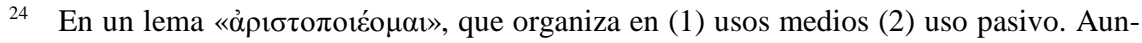
que la forma activa que podemos inferir del sentido de la pasiva no es el factitivo de la media

EMERITA (EM) LXXIII 2, julio-diciembre $2005 \quad$ pp. 263-302 ISSN 0013-6662 


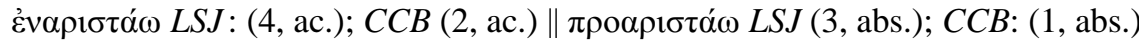

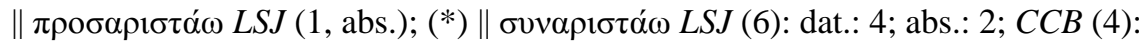

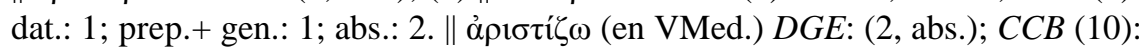

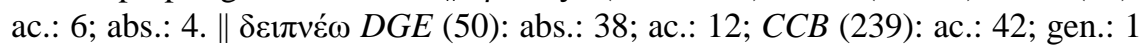
(rel., Hp., Diaet. 70.27); prep.+gen.: 1 (indicando la fuente, Ar., Plu. 890); abs.:

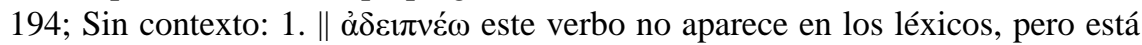
documentado abs. entre los Anonymi medici en el tratado De diaeta 1.3 (Physici

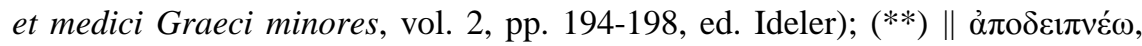

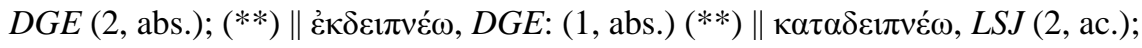

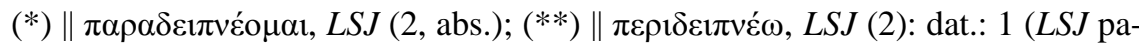
rece considerarlo abs.); VPas.: $1 ;\left({ }^{* *}\right) \| \pi \rho \circ \delta \varepsilon \imath v \varepsilon \dot{\omega} \omega, L S J$ : (1, abs.); $C C B$ (2, abs.)

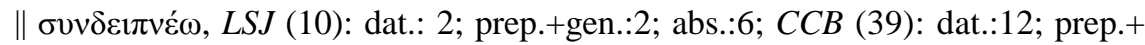

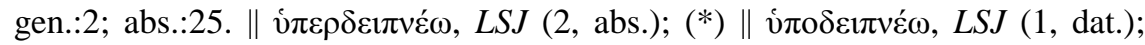

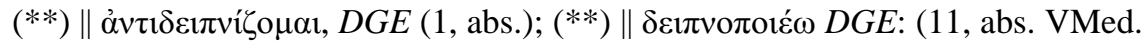

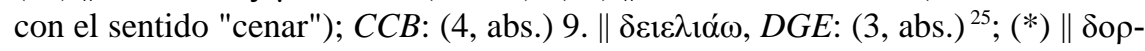
$\pi \varepsilon ́ \omega, D G E:(2$, abs.); (*) $\| \mu 1 \alpha \rho о \varphi \alpha \gamma \varepsilon ́ \omega, L S J:(1$, abs.); (**).

7.2.4: Verbos derivados del nombre de un alimento, o de la palabra para "ali-

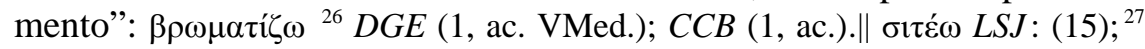
abs.: 5 (seguido de «etc.»), ac.: 8 («feed on, eat»), prep.+gen.:1; prep.+dat («eat of»): 1; $C C B$ (60): ac.: 41; gen.: 1 (rel., Ar., Eccl. 665); prep.+gen.: 1; abs.: 17.

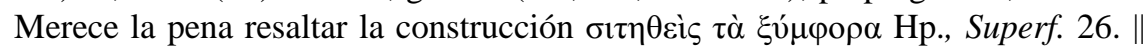

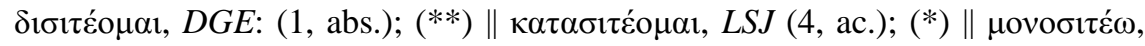

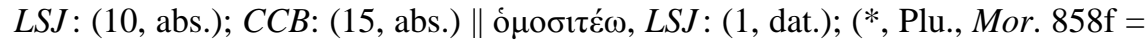

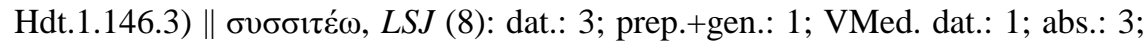

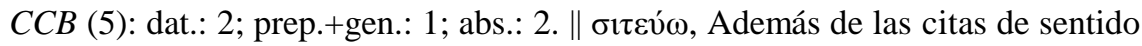

(como sí ocurre en tantos otros verbos de "beber") es preferible dar el lema en forma act. (como hacen $L S J$ y Bally, y el propio DGE s.v. $\delta \varepsilon ı \pi v o \pi$ oté $\omega$ ), y organizarlo en (1) usos transitivos de la VAct. y VPas.; y (2) usos intran de la VMed. Además, tardiamente (en los Excerpta Polyaeni y en escritores eclesiásticos desde el s. IV) está bien testimoniado un uso intransitivo de la VAct. No conozco ningún ejemplo con gen.

25 Pese a la trad. de $D G E$, es verbo de "beber".

26 DGE incluye en el mismo apartado los usos transitivos de la VAct. y el único ejemplo

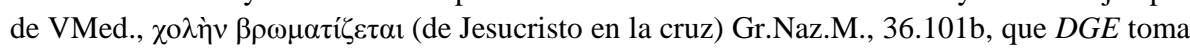
por pas. y al que adjudica el sentido "verse obligado a comer", que es imposible: se trata del normal uso de la voz media (desconocida para $L S J$ ) con el sentido "comer", y por tanto lo considero en este estudio. En nuestro corpus sólo está atestiguada la forma factitiva activa en

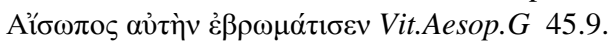

$27 L S J$, que abre lema en v. act., advierte de que la forma activa está documentada como uaria lectio en Hp., Nat.Hom. 9 y en Hesiquio. Fuera de los léxicos como Hesiquio y los escolios, no he encontrado una forma activa o pasiva que justifique un lema en v. act.

EMERITA (EM) LXXIII 2, julio-diciembre 2005 pp. 263-302 ISSN 0013-6662 
factitivo (en VAct. y VMed.) LSJ sólo recoge 1 ej. con el sentido "alimentarse" en VPas. (afirma $L S J$ ) con ac. Plb.12.2.5; En $C C B$ encontramos con el mismo sentido, además del mismo caso (que creemos VMed.) otros dos más: Hp.Nat.-

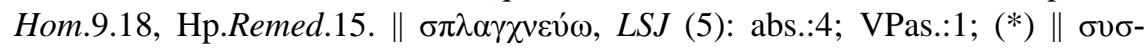
$\pi \lambda \alpha \gamma \chi v \varepsilon v ́ \omega, L S J$ (1, prep.+ gen. indicando compañía.) (*) \| $\sigma \pi \lambda \alpha \gamma \chi v i \zeta \omega, L S J(2)$ :

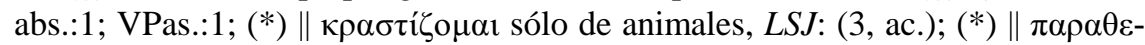
рí $\omega, \operatorname{LSJ}(2$, ac.); (*) \| oivo oivo abs.); $C C B$ : (7, abs.).

7.2.5. Extensiones metafóricas o metonímicas de las operaciones relaciona-

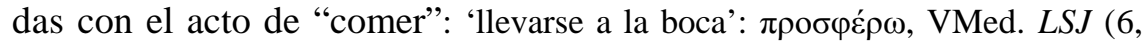

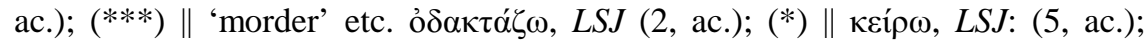
(***) $\| \pi \alpha i \omega$, con sentido «devour» $L S J(2$, ac. $) ;(*) \| \varphi \lambda \alpha^{\prime} \omega$, con sent. «eat up»

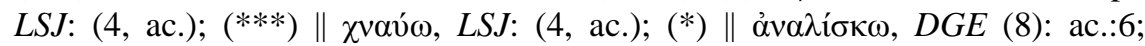
abs.:2; (***) \| $\pi \alpha \rho \alpha \xi \dot{\varepsilon} \omega$, sólo de animales LSJ: (3, ac.); (*) \| $\pi \alpha \rho \alpha \xi v ́ \omega$, sólo de animales $L S J:(4$, ac.); (**) $\| \pi \varepsilon \rho \imath \xi u ́ \omega$, sólo de animales $L S J$ : $(1$, ac. $) ;(* *) \|$ 'sor-

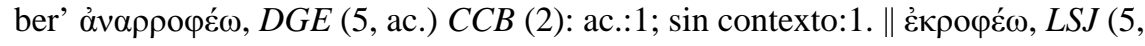

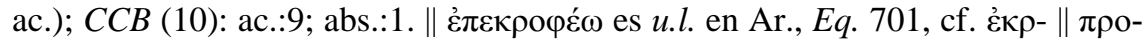

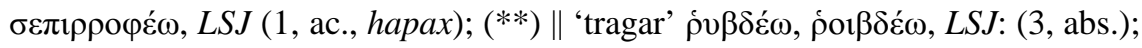

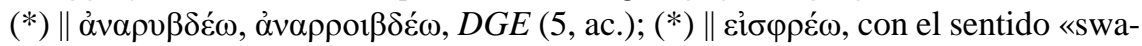

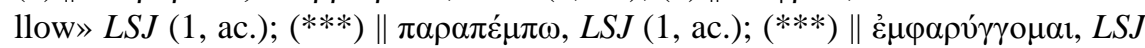

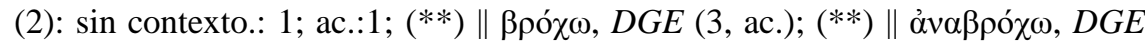

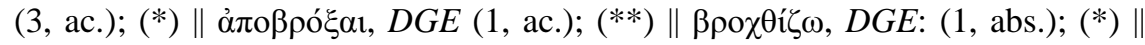

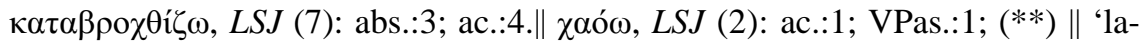
mer', 'chupar' $\lambda \alpha \varphi v ́ \sigma \sigma \omega, \operatorname{LSJ}(6$, ac.); $C C B(4$, ac.) $\| \dot{\varepsilon} \pi \imath \lambda \alpha \varphi v ́ \sigma \sigma \omega, L S J$ : (1, ac.);

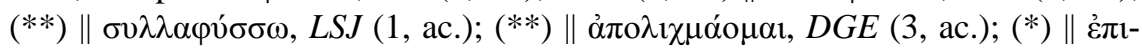

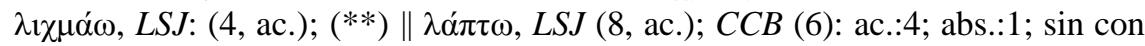
texto:1. \| $\dot{\alpha} \pi \mathrm{\alpha} \alpha \dot{\alpha} \tau \tau \omega, D G E(2$, ac. $) ;(*)$.

7.2.6. Extensiones metafóricas o metonímicas de las operaciones de tomar o repartir la comida: 'tomar' ảvakó $\tau \tau \omega, D G E$ (5, ac.) CCB (8): ac.:7; abs.:1. \|

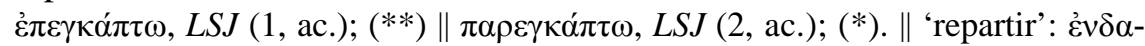

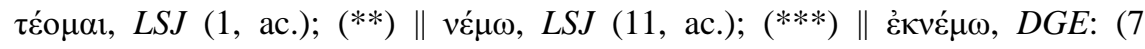

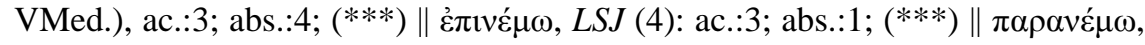

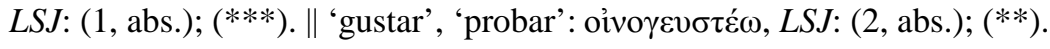

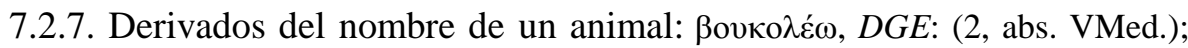

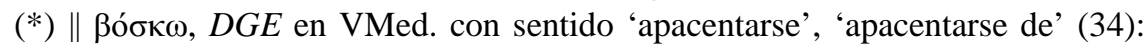

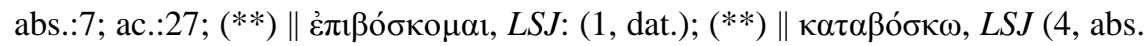
VMed.); (***). 
7.3. Verbos que alternan la construcción con gen. y ac. (18 ejs.)

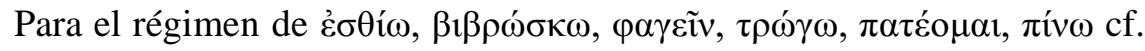
supra.

7.3.1. Derivados de (6.1): $\dot{\varepsilon} \mu \varphi \alpha \gamma \varepsilon \tilde{v} \operatorname{LSJ}$ (10): ac.:6; abs.:4; $C C B$ (15): ac.:6; gen.:1; abs.:8. El ejemplo de gen. (no recogido en los léxicos) es Plu., Art. 3.2 (Grupo A.4) || غ̇ं abs.:3. Los primeros usos que testimonian la construcción de gen. indican claramente la acción de 'morder' por oposición a 'comer', lo que no siempre ha sido

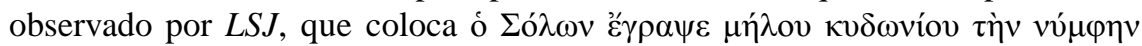

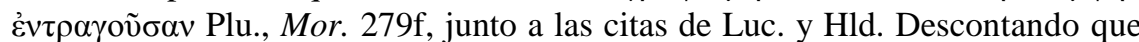
la atribución a Solón sea correcta, y fuera cual fuera la construcción o el verbo

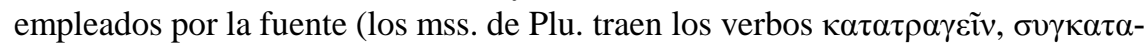
$\tau \rho \alpha \gamma \varepsilon \tilde{v} v$ y $\dot{\varepsilon} v \tau \rho \alpha \gamma \varepsilon \tilde{v} v$ en los distintos pasajes que transmiten esta anécdota) parece que la acción es "morder el membrillo" (para evitar el mal aliento) y no comerlo (para lo que no veo la justificación). El verbo pasa a la categoría de "comer" referida a alimentos que se mastican de forma insistente (esp. a la manera de los rumiantes) como los frutos secos, y de ahí viene a dar un presente para $\varphi \alpha \gamma \varepsilon i v$,

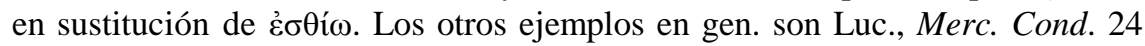

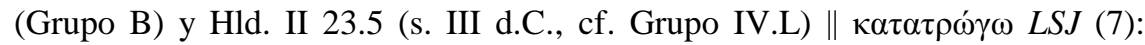
ac.:6; gen.:1 seguido del conocido «etc.»; $C C B$ (5): ac.:1; gen.:2; VPas.:1; abs.:1. Los ejemplos con gen. son Plu., Art. 3.2 (cit. por $L S J$, Grupo A.4) y ó $\Sigma$ ó $\omega \omega v$

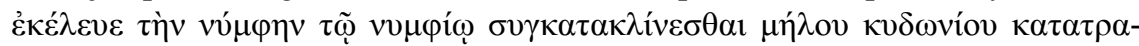

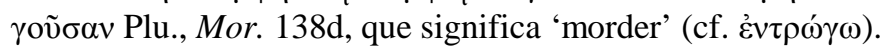

7.3.2. Derivados del nombre de un alimento, o de la palabra para 'alimento': $\alpha$ $\kappa \rho \alpha \tau i \zeta \omega$ en VMed. $D G E(5)^{28}$ : abs.:2; ac.:2; gen.:1; $C C B$ (3): ac.:2; abs.:1. $\dot{\alpha} \mu 1 \gamma o \tilde{\varsigma} \varsigma \grave{\eta} \kappa \rho \alpha-$

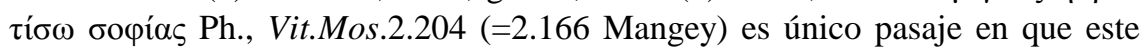

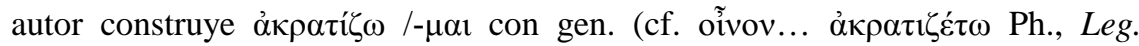

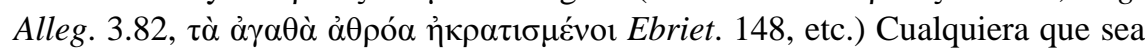
la explicación que se dé a esta construcción, el sentido no puede ser 'desayunar', como quiere el $D G E$, que no da sentido ni aun tomándolo metafóricamente. El verbo retiene aquí su sentido 'beber vino sin mezcla' (del que se deriva el uso 'almorzar') como bien indica el complemento y exige el sentido. Cf. Grupo G. \| $\varepsilon \dot{\varepsilon} \mu \rho \omega \mu \alpha \tau i \zeta \zeta, L S J(3)$ : abs.:2; gen.:1; (**). Aunque es una vox lexicorum, damos aquí la única construcción de gen. testimoniada: $\delta \varepsilon \varepsilon \varepsilon \lambda i ́ \eta \sigma \alpha \varsigma \tau \tilde{\eta} \varsigma \delta \varepsilon i ́ \lambda \eta \varsigma ~ \varepsilon ̇ \mu \beta \rho \omega \mu \alpha$

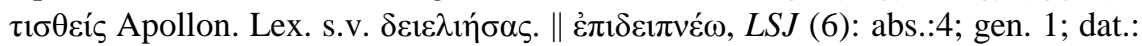
1 (rel.); $C C B$ : (5, abs.). El caso solitario de construcción c gen. citado en $L S J$ es

28 Lematizado en VMed, pero hay inscripciones del s. I d.C. en v. act. c. el sentido 'invitar a'.

EMERITA (EM) LXXIII 2, julio-diciembre $2005 \quad$ pp. 263-302 ISSN 0013-6662 
Alex. 242 K. (=242 K.-A.) del Grupo B. \| $\pi \alpha \rho \alpha \sigma i \tau \varepsilon \dot{\omega} \omega$ con el sentido «play the parasite» tenemos, $\operatorname{LSJ}$ (7): abs.:4; dat.: 1; ac.:1; gen.:1 (Socr., Ep. 1.4); $C C B$ (2): dat.:1; abs.:1. En la ed. de Socr., $E p$. que $L S J$ dice seguir aparece la conjetu-

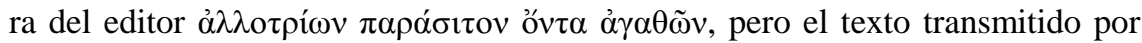
los manuscritos es $\pi \alpha \rho \alpha \sigma i \tau o v ̃ v \tau \alpha$, aceptado modernamente por Köhler, aunque dé una sintaxis poco corriente (por razones ajenas al caso del verbo). Es casi imposible aceptar como auténtica la fecha propuesta por $L S J$ para este escrito (s. V/IV a.C.!!). Más realistamente, basándose en la fecha de los primeros papiros, Köhler coloca el terminus ante quem en el s. III p.C.

7.3.3. Extensiones metonímicas de las operaciones relacionadas con el acto de "comer": 'tomar' (para llevarse a la boca): $\pi \rho \circ \sigma \alpha i ́ \rho \omega$, en VMed. LSJ (6 ejs.): ac.:5; gen.:1 (Gal., UP 11.336, Grupo A.1); (***) $\|$ кá $\tau \tau \omega, L S J$ (12): ac.:8; gen.:1 (Telecl. 33, Grupo A.4); abs.:3; $C C B$ (13): ac.:7; abs.:6. \| (B) 'morder', 'sorber', 'chupar' $\pi \alpha \rho \alpha \chi v \alpha v ́ \omega$, de animales $L S J$ (1, gen. en Ael., NA 1.47 (s. II/ III d.C.); (**) \| gen.:1 (Luc., Lex. 5, considerado part., pero cf. Grupo B); abs.:5; CCB (88): ac.:65; gen.:8 (todos en Corpus Hippocraticum, todos Grupo D); abs.:15. || $\dot{\alpha} \pi \mathrm{o}-$

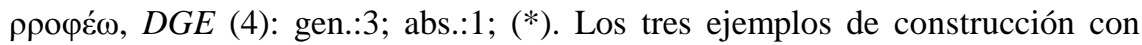

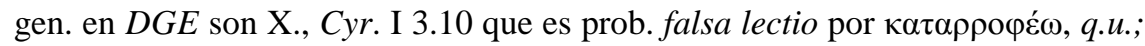
Synes., Ep. 120 (cf. Grupo A.3) y Posid. 67.32 que es gen. de origen. \| غ̇ंıрро-

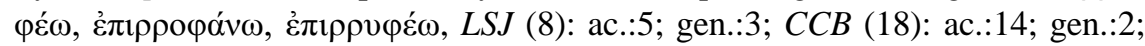
VPas.:1; abs.:1. Ael., NA 14.5 es gen. de origen, Theopomp. Com. 76 se explica en Grupo F. Plu., Phoc. 9.9 y Hld. II 23.5 (de $C C B$ ) pertenecen al Tipo IV. \|

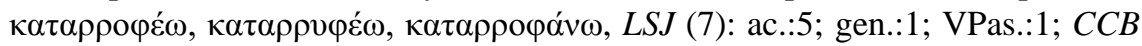
(7): ac.:4; gen.:1; abs.:2. El ejemplo de $L S J$ es Orib. VIII 6.16 (s. IV d.C., Tipo

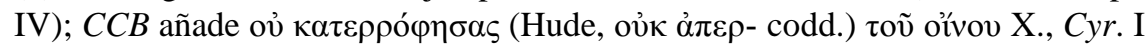

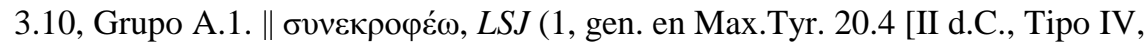
es hapax]) \| $\sigma \pi \alpha ́ \omega$, el sentido 'chupar' es muy secundario, LSJ (10): ac.:8; gen.:1; VPas.:1; (***) El único ejemplo con gen. es Apollod. 1.143, (Grupo A.1) aunque probablemente no signifique 'chupar', sino 'sorber'. \| $\lambda \varepsilon^{\prime} \chi \omega L L S J$ (6): ac.:5; gen.:1; $C C B$ (27): ac.:22; gen.:2 (1 «ảંò кoเvoũ» en Hdt. IV 172.4);

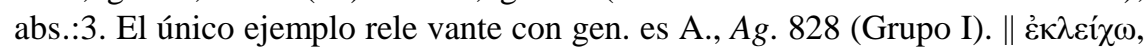
$D G E$ (13): ac.:9; Abs.:1; VPas.:3; CCB (4) ac.:2; gen.:2. Los ejemplos en gen.,

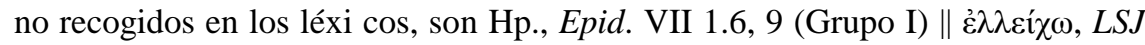
(1, gen.); $C C B$ (2, ac.). El único ejemplo en gen. es el uso figurado Com. Adesp.125 (Meinecke).

7.4. Verbos cercanos a las nociones "comer", "beber" que única o principalmente aparecen testimoniados con genitivo

El sentido principal de todos estos verbos (11+4) es el de (1) "probar", 
"disfrutar" o "llenar" o (2) "Morder", "arrancar de un mordisco", y si alguna vez indican "comer", "beber" (no es seguro que todos lo hagan, y algunos con seguridad caen fuera del grupo), es en usos secundarios, en extensión metonímica o metafórica de su sentido principal. No ofrezco aquí el texto de cada ejemplo, limitándome a ilustrar el uso con algunas citas. El contexto es casi siempre distinto del definido para usos de los tipos I-II que hemos establecido en $\S 8.1$.

7.4.1: "gustar", "probar": $\gamma \varepsilon v ́ \omega, D G E$ (11): gen.:8 (1 recíproco con sentido "comer" Th. II 70.1); abs.:3 (Hp., Epid. III 1.2, Act. Ap. 10.10, Melit. fr. Pap. 58.8); (***): Constr. con gen. e.g. Hp., Mul.1, E., IA 423, Pl., R. 559d, POxy. 1576.4

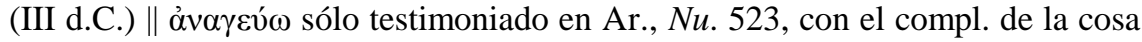

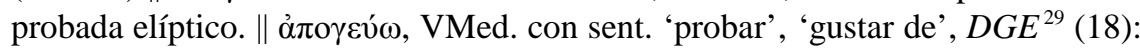
gen.:15 (i.a. Hp., Epid. VII 2, Pl., R. 354b, X., Cyr. I 3.4, Philostr., Im. 1.20, Luc., $A m .42$ ); ac. y gen.:1; abs.:2; $\| \delta ı \gamma \gamma \varepsilon v ́ \omega, D G E^{30}$ (3): gen.:1 (oilvov Gal., Dignosc. Puls. 5 (=8.944.12 Kühn) (II d.C., Grupo G); ac.:2; CCB: elípt.:2. Uno de los ejemplos citados por $D G E$ como rección de ac. lleva en realidad el com-

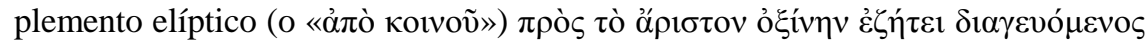

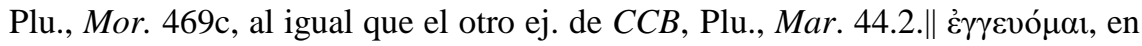
VMed. DGE: (1, gen., cf. Grupo A); (***) $\| \pi \alpha \rho \alpha \gamma \varepsilon v ́ \omega, ~ L S J: ~(3$, gen. VMed.

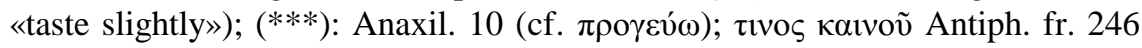

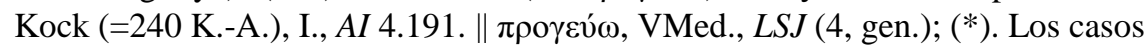

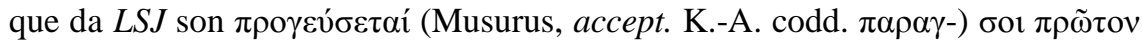

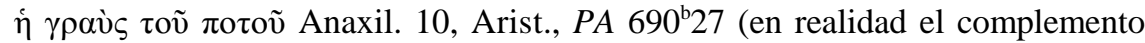
está elíptico); Plu., Mor. 49e (cf. G-A.1), Ph., Mutat. Nom. 164 (=1.603 Man-

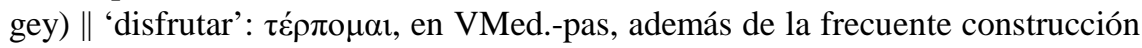
con dat. tenemos $L S J$ (3, gen. «have full enjoyment of») (cf. Küh.-G. Gr.Gr. §

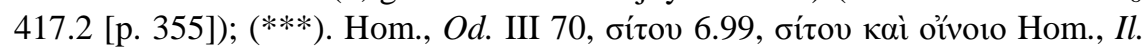

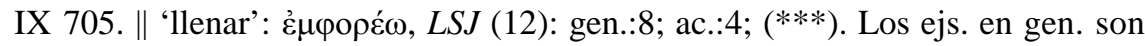

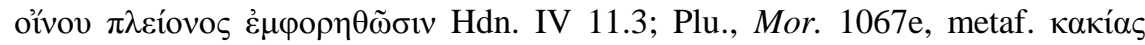

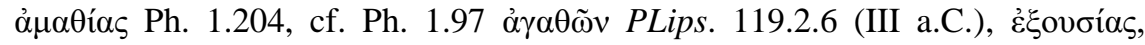

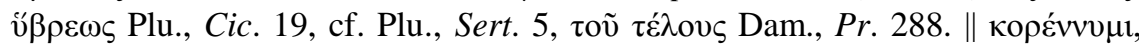

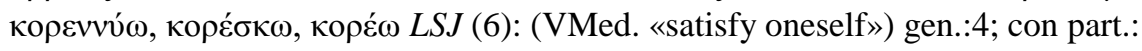
$2 ;(* * *)$.

7.4.2. 'Morder, arrancar un mordisco': $\pi \alpha \rho \varepsilon \sigma \theta i ́ \omega, L S J(3)$ : abs.:1; gen.:2; (*): ò

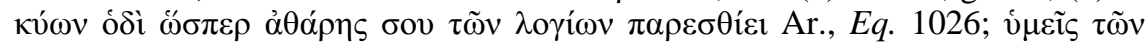
$\pi \alpha \rho$ ' 'Е $\lambda \lambda \eta \sigma \iota ~ \pi \alpha \rho \varepsilon \sigma \theta i ́ \varepsilon \tau \varepsilon \mu \alpha \theta \eta \mu \alpha ́ \tau \omega v$ Iul., Gal. 229c (III d.C.). El sentido de

$29 D G E$ y $L S J$ organizan inconsistentemente los usos activos antes que los medios. Cf. en cambio $\gamma \varepsilon v ́ \omega, \delta 1 \alpha \gamma \varepsilon v ́ \omega$, etc.

$30 \quad L S J$ no incluye los usos con ac., que $D G E$ coloca antes que el ejemplo con gen.

EMERITA (EM) LXXIII 2, julio-diciembre 2005 pp. 263-302 ISSN 0013-6662 
este verbo es difícil de determinar, porque aparte de las tres citas que aporta $L S J$, todas en uso figurado, sólo encontramos con anterioridad la glosa $\pi \alpha \rho \varepsilon \sigma \theta i ́ \varepsilon[\tau \alpha]$ : $\pi \alpha \rho \alpha \beta \imath \beta \rho \dot{\sigma \kappa \varepsilon \tau \alpha \iota ~ H s c h . ~(\pi \alpha \rho \alpha \beta ı \rho \omega ́ \sigma \kappa \omega, ~ u n ~ a d d e n d u m ~ l e x i c i s, ~ e s ~ h a p a x) ~ \| ~}$

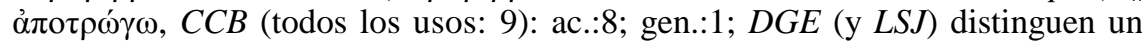
sentido 'cortar a mordiscos', «nibble off» (13, ac.) de otro 'mordisquear', («nibble at»). De este último, $D G E$ (3, gen). Aunque la distinción de sentido es correcta, probablemente algunos de los ejemplos con ac. no indiquen más que la

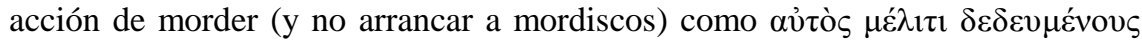

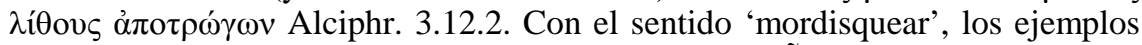

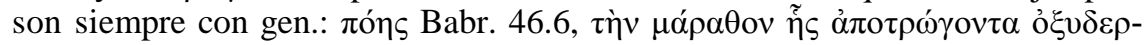

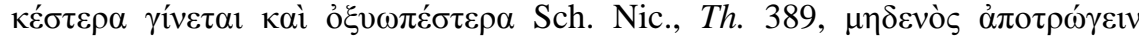

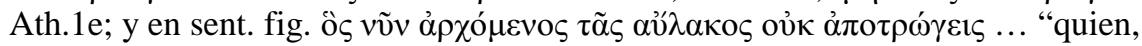
ahora que comienzas, no le muerdes al tajo" Theoc. 10.6, al que $C C B$ añade:

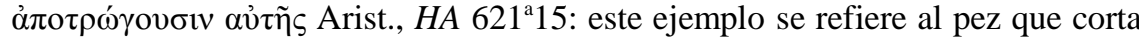
el sedal para librarse del anzuelo, por lo que se excluye el sentido "comer". El ejemplo de Theoc.10.6 parece un giro semejante al español 'hincar el diente' que subraya el comienzo de la acción. $\| \pi \alpha \rho \alpha \tau \rho \omega ́ \gamma \omega \operatorname{LSJ}(5$, gen.); (*). Los casos son:

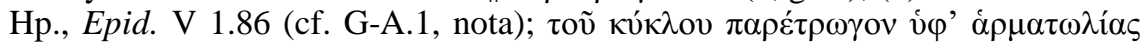

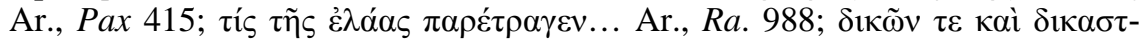

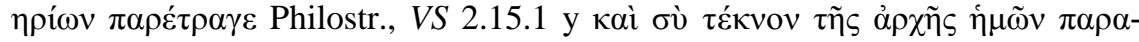
$\tau \rho \omega ́ \xi \eta ̣$ August. ap. Suet., Galb. 4. || Finalmente, considérese el caso de $\delta 1 \alpha \tau \rho \omega ́ \gamma \omega$ con el sent. «mordisquear, mascar» $D G E$ (5) ac.:4; gen.:1; $D G E$ recoge un ejem-

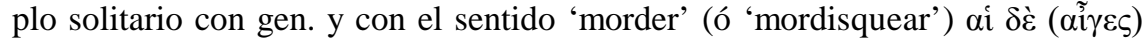

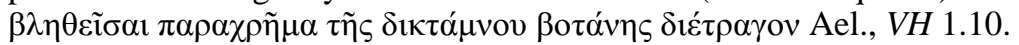

\section{ESTUDIO Y CLASIFICACIÓN DE LAS CONSTRUCCIONES DE "COMER", "BEBER" CON GENITIVO}

\subsection{Clasificación semántica y contextual de los ejemplos}

La siguiente clasificación es una taxonomía de los contextos en que aparecen las construcciones de verbos "comer", "beber" con objeto pasivizable en gen. He registrado si la forma aparece o no con artículo (salvo en los pasajes de Homero), el número gramatical, si el $\mathrm{SN}$ es determinado o no, y si es específico. Las estadísticas sobre todos estos rasgos se pueden ver en $\S$ 8.2. Cuando no indico el caso del complemento, se entiende que es gen. La clasificación incluye todos los ejemplos de este tipo de construcción en gen. que he encontrado en $C C B$ y en los léxicos mencionados en el apartado anterior, salvo naturalmente aquellos ejemplos del corpus que hayan podido escapárseme, y las siguientes construcciones que no son pertinentes para nuestro estudio, que pueden consultarse en el Apéndice de § 10: a) Cons- 
trucciones con gen. de origen que indican el recipiente o contenedor del que se toma el líquido; b) Construcciones con otro tipo de objeto en gen. (de lugar o comparativo); c) Construcciones «ảંò кoเvoṽ» con verbos que rigen gen.; d) Construcciones con gen. relativo. e) textos de autores claramente posteriores al s. II incluidos en un corpus como el aristotélico.

Esta clasificación incluye cuatro tipos, numerados del I al IV, cada uno de los cuales consta de varios grupos (G-A, G-B, etc.). El IV no es propiamente un "tipo", sino un apartado donde he juntado los ejemplos que no cabían en los tipos I/ III. Como ya he dicho, se trata de una taxonomía según el contexto, que no intenta explicar por sí sola los hechos, al menos de forma obvia. Es por tanto muy importante tener en cuenta que si clasifico un tipo de usos según un contexto no es porque el gen. venga exigido por el tipo concreto de situación, sino que espero deducir lo que tales situaciones tengan en común para concluir cuál es el rasgo (o rasgos) que explican la alternancia de caso en el marco predicativo. Intentamos explicar la distribución de los ejemplos en el apartado $§ 9$.

TIPO I [= GRUPOS A, B, C]: El complemento es una sustancia no apta o no idónea para la alimentación

GRUPO A: Objetos generalmente no destinados a la alimentación cuya ingestión tiene un efecto ajeno a su valor alimenticio ( 38 citas, 41 ejs.): El objeto (A.1) es un veneno o similar; (A.2) es sagrado o no se puede comer por razones religiosas; (A.3) son objetos no aptos para la alimentación por otras razones; (A.4) es un sacrificio apto para ser ingerido ${ }^{31}$.

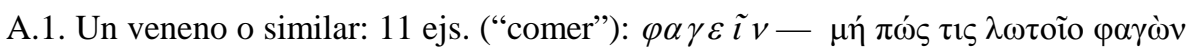

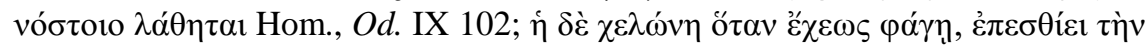
ópíravov "la tortuga, cuando come serpiente, toma como antídoto el orégano"

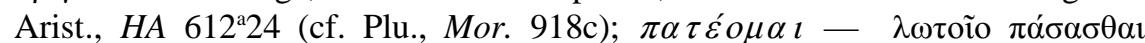

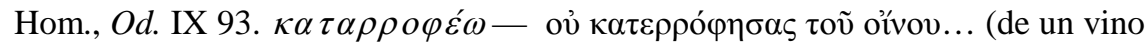

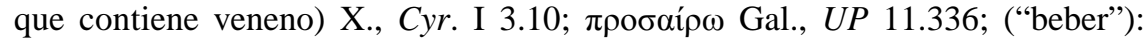

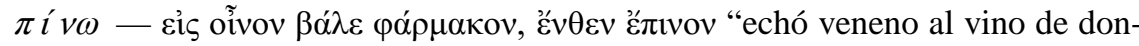

31 Contabilizaré como varios ejemplos dentro de una misma cita cuando hay cambio de sujeto (entiendo que hay una elisión verbal) y también, a los sólos efectos de contabilizar rasgos gramaticales, cuando los sintagmas subordinados tienen una distinta determinación o hay un cambio en el número gramatical. La presencia de los rasgos estudiados del complemento gen. es la siguiente: sg.:24 (60.0\%); pl.: $16(40.0 \%)=40$ ejs. (no contabilizo Hom., Od. IV 220 ; +art.:14 $(44 \%)$; -art.: $18(56 \%)=32$ ejs. (no contabilizo los pronombres); +det.:11 $(27 \%)$; -det.: $30(73 \%)=41$ ejs.; +especif.:20 $(49 \%)$; -especif.: $21(51 \%)=41$ ejs.

EMERITA (EM) LXXIII 2, julio-diciembre $2005 \quad$ pp. 263-302 ISSN 0013-6662 


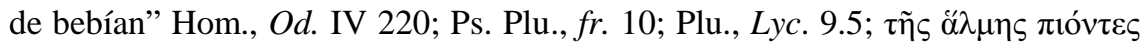
"bebiendo agua de mar" (con resultados fatales) Ach.Tat. III 4.4. A estas citas

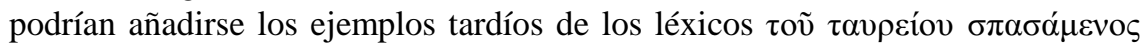

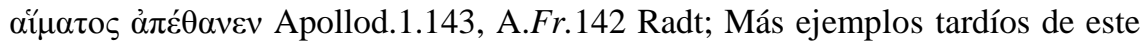
grupo procedentes de $C C B$ (no contabilizados por ser obras apócrifas ó tardías)

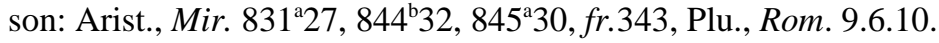

A.2: Alimentos que son objeto de alguna prohibición o tabú: 21 ejs. ("comer"): $\pi \alpha$ -

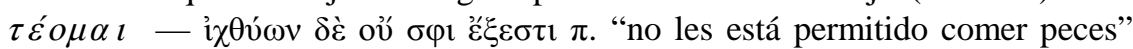

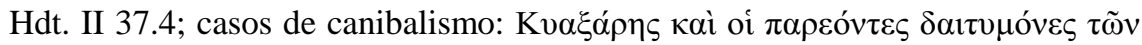

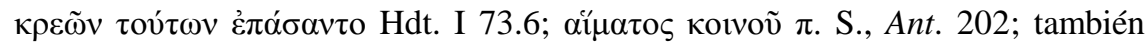

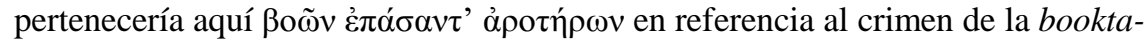

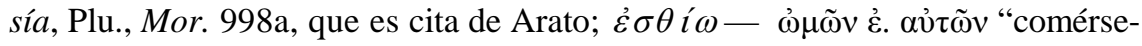
los (a los espartiatas) crudos" X., $H G$ III 3.6 Todos los traductores que he podido consultar eluden una traducción partitiva y lo vierten como un CD ordinario;

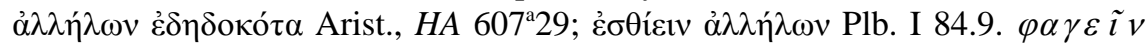

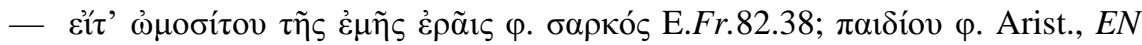

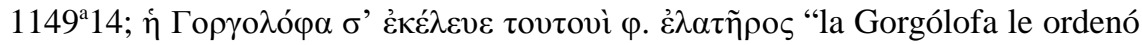
a ese comerse un remero" Ar., Eq. 1181 (juego de palabras con un tipo de bollo

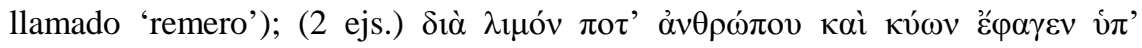

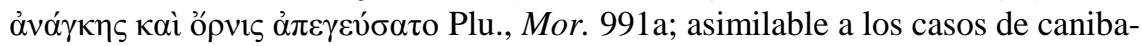

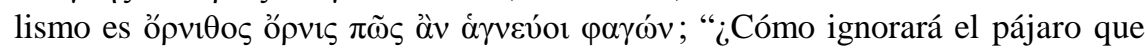
come pájaro?" A., Supp. 226; quizás no necesita otra explicación $\dot{\varepsilon} \gamma \gamma \varepsilon v \dot{v} \omega-$

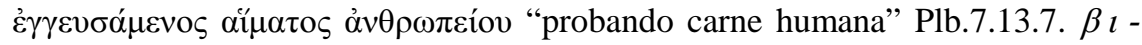

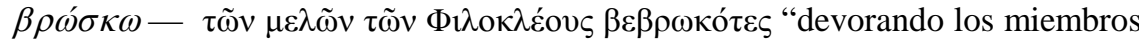
de Filocles" Ar., V. 462 (juego de palabras en el original con 'miembros'/ 'ver-

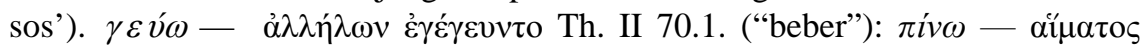

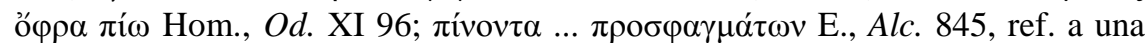
especie de veneno, Pl., $L g$. 647e; ref. a un fármaco que provoca excesiva intrepi-

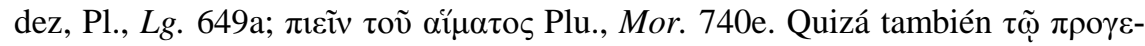

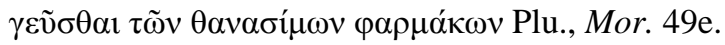

A.3. Objetos no aptos para la alimentación: 2 citas, 3 ejs. (“comer”): $\dot{\varepsilon} \sigma \theta i \omega$ (2 ejs.)

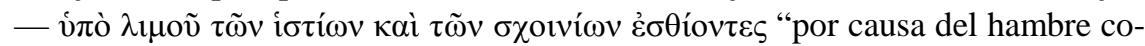
miendo de las velas y las maromas" Plu., Brut. 47.3.5. ("beber") Asimilable a

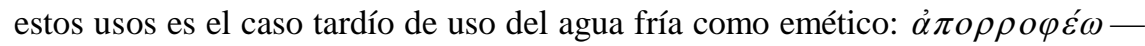

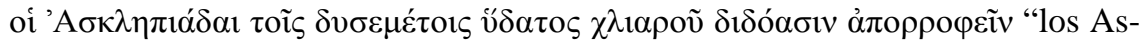
clepiadas dan de beber agua fría a los que no pueden vomitar" Synes., Ep. 120.

A.4. Ofrendas religiosas que pueden ser consumidas: 5 ejs. ("comer"): $\pi \alpha \tau \varepsilon \dot{\varepsilon} o \mu \alpha t$

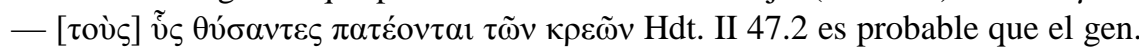
insista en el hecho (narrado luego) de que parte de la carne la echan al fuego, sin

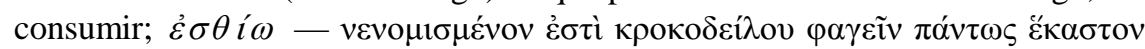

EMERITA (EM) LXXIII 2, julio-diciembre $2005 \quad$ pp. 263-302 ISSN 0013-6662 
"está establecido que cada uno sin excepción coma cocodrilo" Plu., Mor.

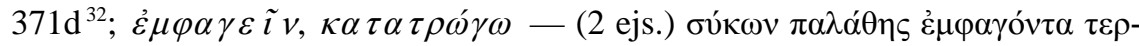

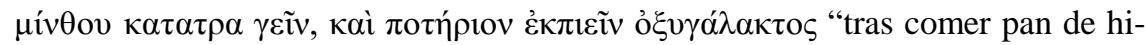
gos (gen.) masticar terebinto (gen.) y beber un vaso (ac.) de leche amarga" (de

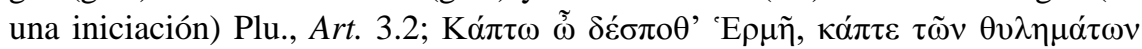
Telecl. 33.

COMENTARIO: Común a todos estos ejemplos (que reúnen casi todos los del ático de $C C B$ ) es el hecho de que el objeto ingerido produce su efecto más relevante por causas no relacionadas con su función alimenticia, es decir, por el mero hecho de ser ingerido (en principio en cualquier cantidad). Las consecuencias son casi siempre negativas (salvo en GA.4), bien por tratarse de sustancias nocivas (aunque evidentemente la medicina griega conocía el efecto acumulativo de la mayoría de los venenos), bien por estar sometidas a severas restricciones de tipo religioso o moral. Los ejemplos de A.4 son en varios aspectos distintos de todos los anteriores, y quizás se trate de auténticos partits. puros. Respecto a los verbos "beber", a pesar de que el uso de este tipo de verbos referido a venenos es muy frecuente, la construcción con gen. no es lo regular: las abundantes referencias a la condena de Sócrates siempre usan en ac. Con verbos "comer" también vemos la construcción de ac. en contextos semejantes (A.Ag.1597, Hdt.9.118.1, etc.).

Grupo B: El contexto implica desdén o menosprecio del objeto. (7 citas, 8 ejemplos)

B.1.: El objeto se presenta como un producto desestimado (3 citas, 4 ejs.) (“co-

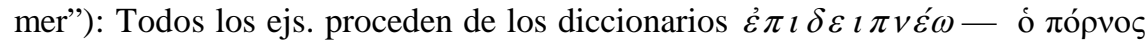
ỡ $\tau$ o

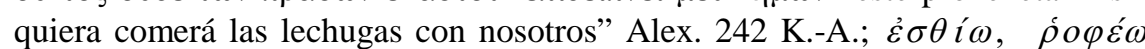

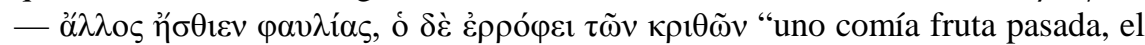
otro sorbía potaje de cebada” Luc., Lex. 5 El texto deja claro el disgusto por tal tipo de comida, a las que en las notas a su traducción, Harmon llama «rubbish».;

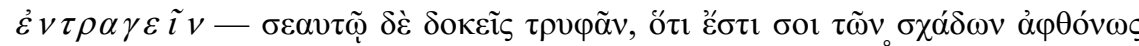
$\dot{\varepsilon} v \tau \rho \alpha \gamma \varepsilon \tilde{i} v$ "te crees que vives en el lujo porque puedes comer higos secos sin freno" Luc., Merc. Cond. 24.

B.2. La elección del objeto se presenta faute de mieux (4 citas, 4 ejs.): $\varphi \alpha \gamma \varepsilon \tilde{\imath} v-$

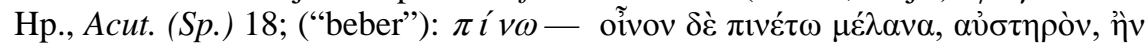

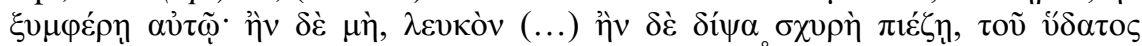

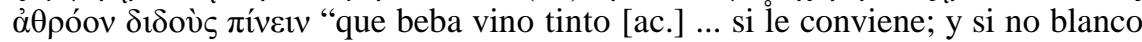
[ac.], y si tiene una gran sed, que se le de a beber agua [gen.] en abundancia"

32 Los traductores suelen entender el texto como si se tratara de un solo cocodrilo, pero ello no está necesariamente implicado, y queda casi excluido en el pasaje aducido como paralelo Hdt. II 69.2.

EMERITA (EM) LXXIII 2, julio-diciembre $2005 \quad$ pp. 263-302 ISSN 0013-6662 


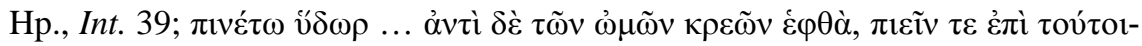
oiv oívov "que beba agua [ac.], y en lugar de la carne cruda, (carne) cocida [ac.]

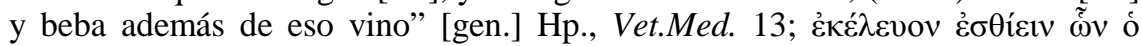

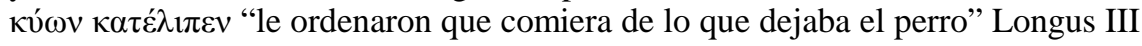
8.2 .

COMENTARIO: Este grupo incluye los dos ejemplos más tempranos que he encon-

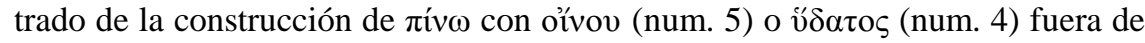
Homero, ambos fuera también del ático, y en oposición a una construcción con ac. sólo unas líneas antes. Es destacable que en ambos casos se trate de un referente indeterminado, pero que en el primero el nominal vaya con artículo, y sin él el segundo.

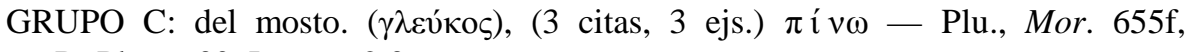
Ps.Plu.Fr.30, Longus 2.36.

COMENTARIO: Si estos ejemplos (todos del s. II d.C.) deben considerarse juntamente (y no es una mera coincidencia), quizás se trate de un giro particular referido a esta bebida substitutiva del vino. En tal caso quizás debería considerárselo un caso particular del grupo anterior. Es posible, sin embargo, que sea solamente un ejemplo del uso tardío del los verbos "beber" rigiendo gen.

TIPO II [G-D, E, F, G]: Construcciones (partitivas o no) asimiladas a las construcciones de apropiación

Propio de este tipo es la frecuente neutralización de la oposición líquido / sólido del objeto verbal (y por tanto neutralización de la oposición "comer"/ beber), o que (semejantemente a lo que ocurría en el tipo I) el objeto bien no sea un alimento, bien se ingiera por razones distintas a su función alimenticia.

GRUPO D. El objeto es un preparado medicinal destinado a ser consumido en diversas ocasiones. (40 ejs.) Este uso sólo aparece en Corp.Hipp. ${ }^{33}$ El consumo se produce típicamente a lo largo de varios días. En el caso de los líquidos se distinguen dos grupos, según el gen. indique: (I) la materia prima sólida de la que se fabrica el bebedizo; (II) la propia bebida. Se trata por tanto de una sustancia ya determinada.

D.1. gen. concertado con ac. (8 ejs.) ('comer'): $\dot{\varepsilon} \sigma \theta i \omega-\tau \tilde{i} \nu \pi$ ov $\omega v \pi$ ó $\delta \omega v$

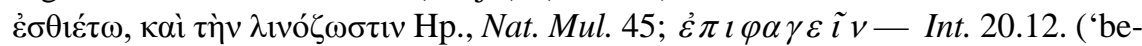
ber'): I: del sólido: $\pi i ́ v \omega-$ Mul. 203; Nat. Mul. 32 lín. 59 Littré (v.1.), Morb. 2.47; $\delta o \varphi \varepsilon ́ \omega-M u l .206$; II: del líquido: $\pi i v \omega-$ Superf. 29 (ampliación de

33 Contabilizo sólo los complementos en gen. sg., 24 (60\%); pl., 16 (40\%); +art., 33 $(82.5 \%)$; -art., 5 (12.5\%) (total número =38 ejs., +2 prons.); +det., 40 (100\%); +especif., 40 $(100 \%)$.

EMERITA (EM) LXXIII 2, julio-diciembre $2005 \quad$ pp. 263-302 ISSN 0013-6662 
Steril. 217); $\dot{\rho} \circ \varphi \varepsilon^{\prime} \omega-$ Int. 30.28 .

D.2. Sólo gen. (32 ejs.) ('comer') $\dot{\varepsilon} \sigma \theta i \omega-$ Nat. Mul. 59, 93, 107; $\varphi \alpha \gamma \varepsilon \tilde{\imath} v-$ Epid. IV 41. ('beber'). I. del sólido: $\pi i$ v $\omega-M u l$. 23, 32 lín. 96 Littré, 60, 78, Nat. Mul. 32 lín. 91 Littré (bis, cf. Mul.112), 35, 109, Int. 44; Morb. 2.52, 7.1, Acut. (Sp.) 38, 93; $\rho$ o $\varphi \dot{\varepsilon} \omega-$ Mul. 78, 117; II. del líquido: $\pi \dot{i} v \omega-$ Steril. 217 (vid. sup.), Steril. 35, 137 y en ac. Steril. 45; Steril. 224; de la bebida usada para la cocción, puesta aparte: Int. 21, 26, 42; Nat. Mul. 132; Superf. 29 lín. 38 (Littré); $\rho$ o $\varphi \dot{\omega} \omega$ - Morb. 2.44.17, Mul. 44, 136; Nat. Mul. 32 lín. 42 (Littré).

Los ejemplos se reparten así según la presencia de un determinante: con art.: 29 (17 sg.; 12 pl.), pron. pers. 2; sin. art. 5 (4 sg., de los que 3 están coordinados con un ac.).

COMENTARIO: Se trata de construcciones de partit. determinado, ceñidas a una situación muy particular: aquella en la que un medicamento preparado con tal fin se toma en sucesivas ocasiones, bien separadas en el tiempo (i.e., en dosis). Con frecuencia el objeto del verbo "beber" es un sólido, lo que parece indicar que la oposición sólido/ líquido puede quedar total o parcialmente neutralizada, con lo que la nota que adquiere relevancia en la definición de la acción verbal es la idea de apropiación de la sustancia de efecto medicinal, y no su forma de adquisición. En comparable situación (el facultativo que receta un medicamento que debe ingerirse) el español moderno usa el verbo de apropiación tomar. Alternativamente puede usarse la construcción con ac.

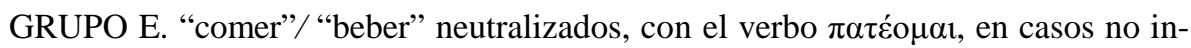
cluidos en (A). Sólo he encontrado este uso en Homero (7 citas, 7 ejs.)

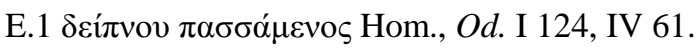

E.2 Fórmulas en que comida y bebida aparecen coordinadas: $\pi \alpha ́ \sigma \alpha \sigma \theta \alpha \imath$ óv $\omega \chi \theta \imath$ oícov kaì oívoro "envía (a los aqueos) a tomar comida y vino" Hom., Il. XIX

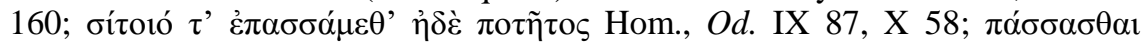

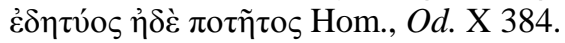

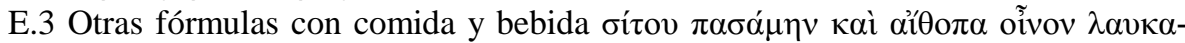

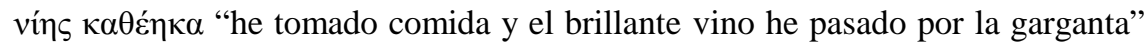
Hom., Il. XXIV 641.

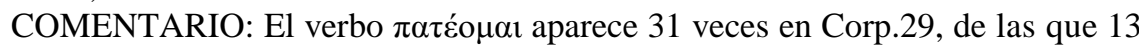
veces lo hace con gen. (con diferencia el porcentaje más alto de los principales verbos "comer"); ac.:14; abs.:4. De los ejemplos con gen., 8 encuentran inmediatamente acomodo en el grupo A, pero otros 7 ciertamente no pertenecen a ese

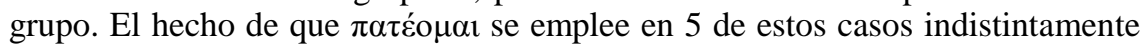
para comida y bebida parece que indica que este verbo puede neutralizarse la oposición sólido / líquido del tipo de alimento, para poner de relieve el rasgo "apropiación de la sustancia" cf. español: comimos carnel bebimos vino/ tomamos carne y vino/ †comimos carne y vinol ††bebimos carne y vino. Que no se

EMERITA (EM) LXXIII 2, julio-diciembre 2005 pp. 263-302 ISSN 0013-6662 
trata de un partit. real, sino de un verbo de apropiación, parecen reafirmarlo los dos ejemplos restantes $(O d .1 .124,4.61)$ puesto que con $\delta \varepsilon i ́ \pi v o v$ no es esperable, en principio, una interpretación partitiva, aun menos en una fórmula como la presente, salvo en contextos que intentan subrayar el hecho de que la comida no se acabó.

Grupo F. El genitivo indica no una comida/ bebida, sino un patrimonio del que se saca para "comer"/ "beber" (5 citas, 5 ejs.)

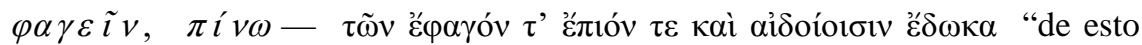

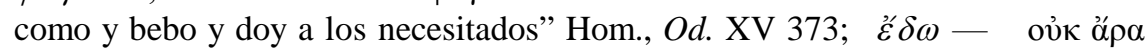

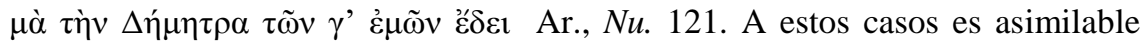

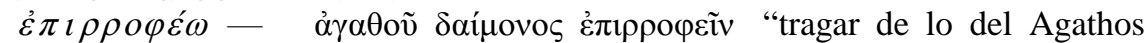

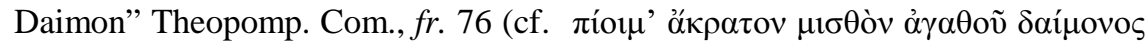
Ar., V. 525). Un texto dudoso y de fecha igualmente incierta (cf. supra) es

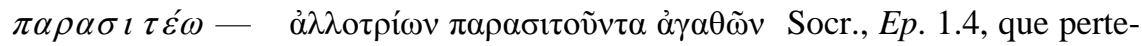
necería a este lugar.

COMENTARIO: Es dudoso si este tipo de construcciones debe considerarse como gen. partit., o si sería mejor clasificarlo entre los de origen, ya que el complemento es compatible con un objeto que indique lo que efectivamente se come o bebe. En cualquier caso parece que de nuevo el rasgo semántico que autoriza la posible interpretación partitiva es la de apropiación de parte de un todo que no es un objeto edible, sino por definición apropiable, omitiendo el las notas que se refieren al proceso de ingestión (y neutralizando la oposición líquido / sólido). Casos semejantes con construcción de ac. son Hom., Od. XXIII 9, 11.116, etc.

Grupo G. Otras construcciones de partitivo con objeto de un gran contenedor (2 ejs.)

La forma particular en la que los griegos consumían el vino en symposia, tomando la mezcla con agua de la cratera y sirviéndolo en copas de las que beben los comensales, necesariamente se refleja en la construcción sintáctica, en donde normalmente el verbo "beber" indica que la acción tiene lugar sobre el vino de la copa, y como hemos visto se construye en época clásica con ac. En el s. II tenemos un testimonio no de consumo normal, sino de cata (lo que normalmente predispone para la

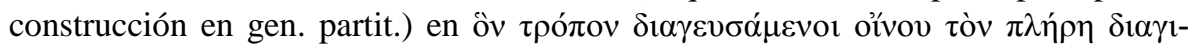

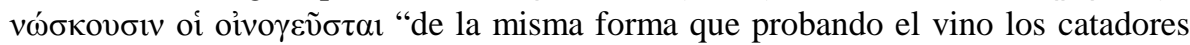

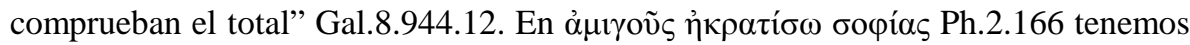
un uso particular, evidentemente figurado, en el que la bebida (esto es, el alimento espiritual) procede figuradamente (y sin mezcla) de un repositorio en que reside la auténtica sabiduría.

TIPO III [= G-H, I]: Construcciones pertenecientes o asimiladas a otros verbos que no implican transformación del objeto. 
Grupo H. Verbos próximos al sentido de "comer", "beber". A este grupo pertenecen los verbos del apartado $\$ 7.4$, que se construyen sólo con gen., y que no son propiamente verbos "comer", "beber".

Grupo I: Con $\lambda \varepsilon i ́ \chi \omega$ y sus derivados (4 ejemplos)

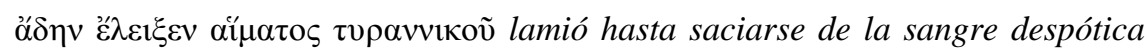

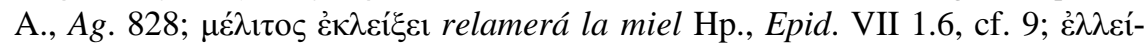
$\chi 0 v \tau \alpha \tau \tilde{\omega} v$ 'A $\theta \eta v \tilde{\omega} v$ relamiendo de los atenienses (i.e. tomando sus costumbres) Com.Adesp.125 (Meinecke).

COMENTARIO: $\lambda \varepsilon^{\prime} \chi \omega$, un verbo que indica un tipo de contacto que no implica la transformación de lo chupado, vacila entre la construcción con ac. (más frecuente) y con gen. (en usos figurados, y dos casos en Hp.) Respecto a A.Ag.828, y como vimos en el grupo A, cuando el objeto está en el suelo, como el agua de un río, la construcción con gen. es más frecuente. Probablemente estos ejemplos deberían asimilarse e los de el grupo $\mathrm{H}$.

\section{TIPO IV: Otras construcciones con genitivo (12 citas, 13 ejemplos)}

En este apartado, que no es propiamente un "tipo", he reunido los ejemplos del corpus de construcciones con objeto gen. que no caben en los tipos I-III. Con excepción de los tres primeros, son todos ellos del s. II d.C. o posteriores.

Grupo J. Construcciones simples con genitivo (3 citas).

Estas pocas citas son los únicos ejemplos claros de nuestro corpus de lo que las gramáticas consideran la construcción habitual en griego clásico.

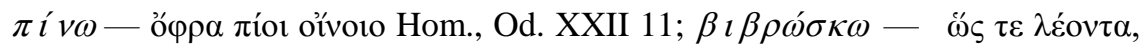

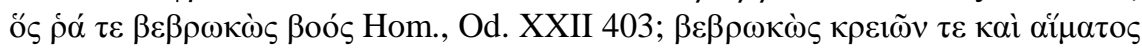
Theoc.25.224.

COMENTARIO: El pasaje de Theoc. parece modelado conforme a la imagen de $O d$., pero en aquél hay de nuevo una neutralización de la oposición "comer"/ "beber" y un interesante cambio en el número gramatical. La imagen en ambas

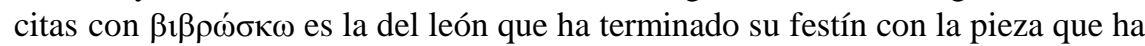
cazado, por lo que la traducción "saciarse de" que recibe a menudo parece adecuada, y se trataría de una construcción como la de los verbos de "llenar".

Grupo K. Partitivo indefinido (2 ejemplos).:

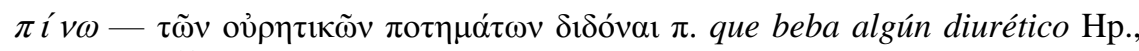

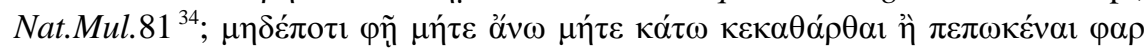

34 He considerado estos ejemplos casos de rección de gen., a pesar de la existencia de ejemplos sin verbo de comer como Hp., Nat.Mul. 61.6 que invitarían a considerarlos simples

EMERITA (EM) LXXIII 2, julio-diciembre $2005 \quad$ pp. 263-302 ISSN 0013-6662 


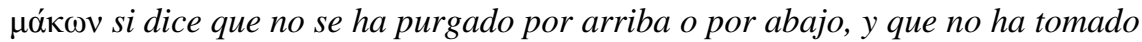
ningún fármaco... Hp., Remed.56.

COMENTARIO: Particular a este tipo de partits. es que la parte que debe entenderse que se toma no es una fracción definida del todo, sino una parte los componentes indefinidos de que se compone el todo; es decir, no individuos sino especies. Véase el uso del artículo.

Grupo L. Procedentes de los autores tardíos (7 citas, 8 ejemplos).

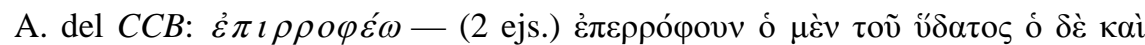

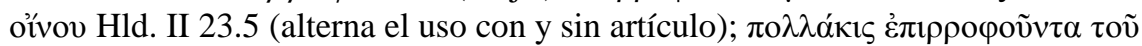

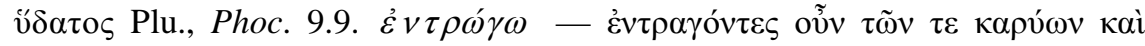

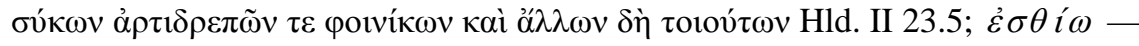

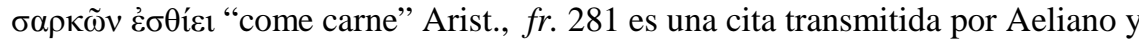
con toda probabilidad la sintaxis de éste autor o una fuente intermedia.

B. de los léxicos: $\pi \alpha \rho \alpha \chi v \alpha v ́ \omega-\tau \tilde{\omega} v \pi v \rho \tilde{\omega} v \pi \alpha \rho \alpha \chi v \alpha \tilde{\sigma} \sigma \alpha$ l "pastar el trigo"

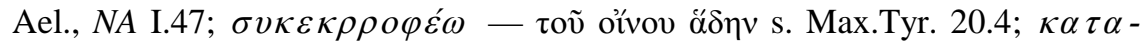

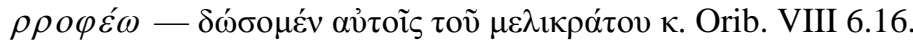

Grupo M. Casos de interpretación dudosa (1 ejemplo).

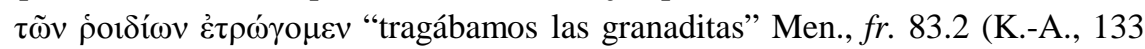

Körte).

COMENTARIO: Desgraciadamente el fragmento está muy aislado para poder interpretarlo con seguridad (el primer verso está corrupto, según todos los editores).

\subsection{Estadísticas sobre otros rasgos relevantes}

Ofrezco aquí una serie de estadísticas acerca de algunos rasgos sintácticamente relevantes del segundo actante en gen. de los verbos "comer", "beber". Estos rasgos son: a) número gramatical [sg./ pl.]; b) presencia o ausencia de artículo [+art./ -art.]; c) determinado o no determinado [+det./ -det.], y d) específico o inespecífico [+específ./ -específ.].

El número total de ejemplos de segundo actante con marca de caso gen. en dependencia de verbos de "comer", "beber" testimoniados en $C C B$ y los léxicos (es decir, todos los grupos ya vistos, menos el $\mathrm{H}$ ) es de 125. Las estadísticas de este apartado se han hecho dejando de lado además los siguientes ejemplos: i) un ejemplo sin contexto suficiente (grupo IV.M); ii) Los grupos $\mathrm{F}$ y G, que indican un contenedor (7 ejemplos), iii) El grupo I, que

construcciones ảंò кoเvoṽ.

EMERITA (EM) LXXIII 2, julio-diciembre $2005 \quad$ pp. 263-302 ISSN 0013-6662 
está más próximo al G-H que a los verbos propios de "comer", "beber" (4 ejemplos); Por lo tanto, las estadísticas se realizan sobre 113 ejemplos. En las estadísticas sobre presencia de artículo, no se cuentan los ejemplos de complemento pronominal (13 ejemplos, de los cuales 3 son relativos). Las estadísticas de la segunda columna se han hecho descontando los 40 ejemplos del Grupo D, es decir, sobre un total de 73 ejemplos.

Tabla 1: Frecuencia de aparición de todos los rasgos considerados [sg./ pl.], [+art./ art.], [+det./ -det.], [+específ./ -específ.]en cifras absolutas y porcentuales: ${ }^{35}$

\begin{tabular}{|c|c|}
\hline "comer", "beber" & Excluyendo el Grupo D \\
\hline $\begin{array}{l}\text { sg.:70 }(62.5 \%) ; \text { pl.: } 42(37.5 \%)=112 \text { ejs. } \\
\text { +art.:60 }(60 \%) ; \text {-art.: } 40(40 \%)=100 \text { ejs. } \\
\text { +det.:54 }(48 \%) \text {; -det.: } 59(52 \%)=113 \text { ejs. } \\
\text { +específ.:62 }(55 \%) ; \text {-específ.: } 51(45 \%)= \\
113 \text { ejs. }\end{array}$ & $\begin{array}{l}\text { sg.:46 }(63.9 \%) ; \text { pl.: } 26(36.1 \%)=72 \text { ejs. } \\
\text { +art.:27 }(44 \%) ; \text {-art.: } 35(56 \%)=62 \text { ejs. } \\
\text { +det.:14 }(19 \%) ;- \text { det.: } 59(81 \%)=73 \text { ejs. } \\
\text { +específ.:22 (30\%); -específ.: } 51(70 \%)= \\
73 \text { ejs. }\end{array}$ \\
\hline
\end{tabular}

Tabla 2: Combinaciones de rasgos [+art./ -art.], [+det./ -det.], [+específ./ -específ.] (doy el listado separado de los pronombres y relativos)

\begin{tabular}{|c|c|}
\hline "comer", "beber" & Excluyendo el Grupo D \\
\hline +art. +det. +específ.,37 (32.7\%) & +art. +det. +específ.,4 (5.5\%) \\
\hline +art. +det. -específ.,1 (0.9\%) & +art. +det. -específ.,1 (1.4\%) \\
\hline +art. -det. +específ.,5 (4.4\%) & +art. -det. +específ.,5 (6.8\%) \\
\hline +art. -det. -específ., 17 (15.0\%) & +art. -det. -específ.,17 (23.3\%) \\
\hline -art. +det. +específ.,6 (5.3\%) & -art. +det. +específ.,1 (1.4\%) \\
\hline -art. +det. -específ.,2 (1.8\%) & -art. +det. -específ.,2 (2.7\%) \\
\hline -art. -det. +específ.,3 (2.7\%) & -art. -det. +específ.,3 (4.1\%) \\
\hline -art. -det. -específ.,29 (25.7\%) & -art. -det. -específ.,29 (39.7\%) \\
\hline pron. +det. +específ.,7 (6.2\%) & pron. +det. +específ.,5 (6.8\%) \\
\hline pron.Refl. -det. +específ.,2 (1.8\%) & pron.Refl. -det. +específ.,2 (2.7\%) \\
\hline pron.Refl. -det. -específ.,1 (0.9\%) & pron.Refl. -det. -específ.,1 (1.4\%) \\
\hline relat. +det. +específ.,1 (0.9\%) & relat. +det. +específ.,1 (1.4\%) \\
\hline relat. -det. +específ.,1 (0.9\%) & relat. -det. +específ.,1 (1.4\%) \\
\hline relat. -det. -específ.,1 (0.9\%) & relat. -det. -específ.,1 (1.4\%) \\
\hline
\end{tabular}

35 Hay un ejemplo de év $\theta \varepsilon v$ que no contabiliza para las estadísticas de número, y otros 13 de pronombres y relativos que no contabilizan en las estadísticas sobre presencia de artículo.

EMERITA (EM) LXXIII 2, julio-diciembre 2005 pp. 263-302 ISSN 0013-6662 
Tabla 3: Combinaciones de rasgos [+det./ -det.], [+específ./ -específ.].

\begin{tabular}{|l|l|}
\hline "comer", "beber" & Excluyendo el Grupo D \\
\hline +det. +específ.,51 (45.1\%) & +det. +específ.,51 (45.1\%) \\
+det. -específ.,3 $(2.7 \%)$ & +det. -específ.,3 $(2.7 \%)$ \\
-det. +específ.,11 $(9.7 \%)$ & -det. +específ.,11 $(9.7 \%)$ \\
-det. -específ.,48 (42.5\%) & -det. -específ.,48 (42.5\%) \\
\hline
\end{tabular}

\section{CONCLUSIONES}

\subsection{Resumen de los datos}

Como puede verse en $\S 8.2$, hay una clara diferencia entre las estadísticas del grupo D (el más claramente partit.), donde predominan los complementos determinados y específicos, y el resto de los grupos, que ofrecen una interpretación frecuentemente menos clara, donde predominan los no determinados ni específicos. Podemos resumir el complejo panorama del régimen verbal en gen. con estos verbos de la siguiente manera:

I) Cercanos a los verbos de "comer", "beber", pero sin ser propiamente este tipo de verbos (por carecer de alguna o varias de las notas definitorias) observamos una serie de verbos (9 lemas) que en cualquier época se construyen única o casi exclusivamente con gen. Son por un lado $\gamma \varepsilon v ́ \omega$ y varios de sus compuestos, y por otro $\tau \dot{\varepsilon} \rho \pi$ sintácticamente más próximos a los de "probar", "coger", "tomar", "gustar", si es que no pertenecen plenamente a estos grupos.

II) Más próximos al núcleo semántico de "comer", "beber", o formando parte plena del mísmo, hay un número no pequeño de verbos que construye su $\mathrm{CD}$ con marca de ac., pero que puede admitir la marca de gen. con una frecuencia que parece superior a la ordinaria aparición de un gen. partit. con verbos que implican una afectación alta del objeto. ${ }^{36} \mathrm{El}$ núcleo de esta clase lo constituyen los principales verbos "comer", "beber", y además una serie de verbos que implican el mismo tipo de nociones semánticas que los de la periferia mencionados anteriormente, generalmente con preverbio. Cuando este tipo de verbos está bien testimoniado, durante el periodo considerado la frecuencia del ac. es muy superior a la del gen.

36 A falta de estadísticas sobre el uso del gen. adverbal con otro tipo de verbos en un corpus amplio, he debido extrapolar los datos ofrecidos por las gramáticas, y los del corpus de nuestra tesis. Los verbos que sí contienen la noción partitiva en su lexema (como $\mu$ sípo $\mu \alpha$, etc.) normalmente exigen el caso gen., aunque impliquen transformación del objeto.

EMERITA (EM) LXXIII 2, julio-diciembre 2005 pp. 263-302 ISSN 0013-6662 
III) Por otro lado vemos un buen número de verbos (111) que sólo admiten la marca de ac. en el objeto, o una construcción abs., y que típicamente están caracterizados al menos por dos notas: (a) semánticamente, la afectación del objeto de tales verbos está especialmente resaltada, bien por ser verbos intensivos, bien por incluir en su semántica el tipo de comida de que se trata, o finalmente, por que subrayan el paso de la comida por el organismo. También se debe incluir en este grupo los que necesariamente implican un suj. animal., salvo cuando el sentido es "masticar". (b) Rasgos morfológicos: Una parte de ellos son derivados adnominales de un sustantivo de "alimento", y

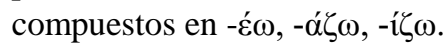

9.2. Hipótesis sobre la asignación de marca del objeto de los verbos de "comer" y "beber"

De los anteriores datos deducimos la siguiente hipótesis que explique la marca de caso del objeto en gen.: Entre los verbos que en griego clásico, y hasta al menos el s. II d.C. admiten una construcción con gen., podemos distinguir dos situaciones o tipos:

a) Verbos que adquieren el valor semántico "comer" a partir de una extensión metafórica o metonímica del sentido de un corto número de verbos de transitividad reducida o de doble objeto, cuya semántica en griego clásico exige o permite un complemento en gen. (Tipo III del $\S 8.1$ ). Estos grupos son: $(\alpha)$ Verbos "coger", "tocar". Ninguno de estos verbos incluye la idea de "tragar" (hacer pasar la comida al estómago) dentro de su definición, y por tanto su semántica no implica la transformación del objeto sobre el que recae la acción. A falta de ese parámetro, deben considerarse como verbos que presentan afectación débil del objeto, y por tanto, de transitividad reducida. Su sinta-

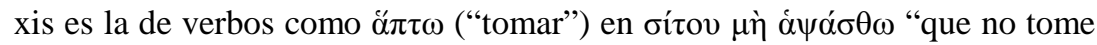

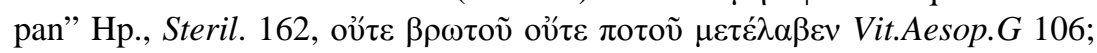

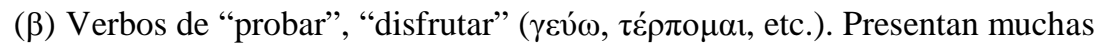
semejanzas semánticas con el grupo anterior, principalmente (en lo que toca a la presente cuestión) el hecho de que el objeto no debe ser consumido, y por tanto no hay modificación del mismo. La marca de gen. indica igualmente una transitividad reducida. $(\gamma)$ Verbos de doble objeto como "llenar" que construyen el segundo complemento en gen. (una explicación sobre el caso gen. del

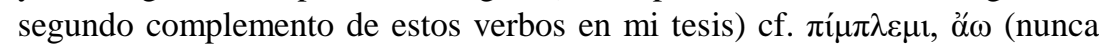
testimoniado con el sentido "saciarse de comida", según $L S J$ ).

En este grupo (a) se incluyen todos los verbos que única o principalmente se encuentran testimoniados en gen. La mayoría de los verbos, en cambio, testimonia simultaneamente, con una semántica más o menos cercana, una

EMERITA (EM) LXXIII 2, julio-diciembre $2005 \quad$ pp. 263-302 ISSN 0013-6662 
construcción con ac. (a menudo alternando también con voz activa) que indica una afectación fuerte del objeto.

b) Verbos propiamente "comer", "beber" que dentro del marco cronológico de nuestro estudio se construyen habitualmente en ac., pero pueden admitir un complemento en gen. en ciertos contextos semánticos determinables, y que son casi exclusivamente los siguientes: $(\alpha)$ cuando su consumo tiene grandes consecuencias (normalmente graves) indiferentes de su valor como alimento (que generalmente no poseen); y ( $\beta$ ) cuando la acción presenta una o (generalmente) varias de estas notas simultaneamente: (i) neutralización de la oposición sólido/ líquido; (ii) el objeto no es un alimento, o su función no es propiamente alimenticia; (iii) el objeto se ingiere en dosis a lo largo de un periodo más o menos extenso de tiempo.

Una parte de estos usos tiene una sencilla interpretación partitiva: el caso más claro es el del Grupo D del $§ 8.1$, en donde, de una cantidad delimitada de medicina a la que ya se ha hecho referencia, se van consumiendo las dosis recetadas. En el resto de los casos, generalmente referidos a un complemento no específico ni determinado, parece que la interpretación partitiva no es generalmente condición suficiente para determinar el uso del gen., sino que ésta aparece sólo en contextos en los que se desea insistir sobre la cualidad del objeto ingerido, un objeto no típicamente alimenticio. En algún caso, la interpretación partitiva es muy discutible (v. gr. X., HG III 3.6, Hom., Od. I 124). Finalmente, es posible que verbos como $\beta \imath \rho \omega ́ \sigma \kappa \omega$ puedan en tales contextos asimilarse a los verbos del tipo (a).

Las construcciones recíprocas (y las reflexivas) con gen. exigen otro tipo de explicación. Este tipo de pronombres emplean con frecuencia el gen. o un sintagma prep. para marcar el argumento objetivo de verbos que, con otro tipo de complemento, exigen el ac., y para ello podemos encontrar una explicación genérica. La diferenciación entre el agente y el paciente es uno de los parámetros de la escala de transitividad: las oraciones más transitivas poseen esta diferenciación, por lo que podemos esperar que en situaciones en las que se da una identidad en el referente del sujeto y el objeto la marca del argumento pueda expresar esta transitividad reducida. ${ }^{37}$ Además de esta explicación, que a mi juicio justificaría la elección de la marca de gen., por razón obvia de la semántica verbal cualquier construcción recíproca o reflexiva con verbos de "comer" (como los tres ejemplos de $C C B$ ) resultan ser perfectas ilustraciones de nuestro Grupo A, por lo que es probable que la semántica

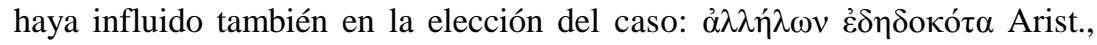

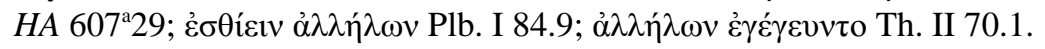

37 Sobre todo ello, cf. nuestra tesis, Riaño 2004 § III.3.7, III.16-17., y esp. Riaño 2006b.

EMERITA (EM) LXXIII 2, julio-diciembre 2005 pp. 263-302 ISSN 0013-6662 
En conclusión, y para el período considerado del griego antiguo, opino que (con escasísimas excepciones, casi siempre tardías o de interpretación dudosa) los verbos propiamente de "comer, beber", que deben en principio considerarse como de transitividad alta, admiten la construcción con gen. en dos situaciones: I) Con muchas restricciones, cuando designan una parte definida o indefinida de un todo determinado; II) En contextos en los que el rasgo "transformación del objeto" desaparece del concepto léxico debido a que el objeto no es un producto que sirva típicamente para satisfacer la necesidad de comer o beber: el verbo pasa entonces a ser tratado sintácticamente como un verbo de transitividad reducida, quizás asimilados a una parte de los verbos de "apropiación" ${ }^{38}$. Debe destacarse que la construcción partitiva de (I) sólo excepcionalmente se da en contextos que no son a la vez del tipo (II), los cuales se presentan generalmente con complementos no determinados.

Semánticamente, lo más relevante en ambas situaciones es la naturaleza del objeto tomado y el uso que se le da, y no la cantidad del mismo o la función alimenticia que satisface. Argumentos a favor de esta hipótesis son i) naturalmente el carácter marginal de los contextos donde aparece la construcción; ii) la indiferencia respecto a la oposición sólido/ líquido del tipo de sustancia consumida y iii) el uso frecuente (dentro del griego, y en otras lenguas) de verbos de apropiación con sentido "comer", "beber", con frecuencia presentando total o parcialmente semejantes restricciones. En el caso de los verbos de "masticar", el gen., por oposición al ac., debe ser una marca de acción durativa, atélica, frente al télico "comer", y no una marca de partit.

Los verbos "comer", "beber" indican acciones cotidianas en la vida del individuo y su actividad social. Son actividades de primordial importancia para su mantenimiento, que se despliegan en gran cantidad de situaciones y sobre una enorme variedad de objetos, por lo que no es extraño que su conceptualización pueda en ocasiones determinadas omitir, o dejar en la sombra, algunas notas del contenido fáctico de tal actividad (la ingestión de alimento, y su efectiva transformación) para poner en relieve otras, que omiten la referencia a la transformación experimentada por el objeto.

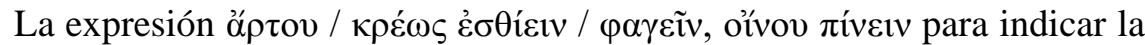
acción de quien bebe de una copa o toma el pan como simple alimento (o

38 Es posible que esta construcción en gen. con verbos de apropiación sea más frecuente con verbos que indican una acción que se realiza con las manos.

EMERITA (EM) LXXIII 2, julio-diciembre $2005 \quad$ pp. 263-302 ISSN 0013-6662 
cualquier construcción semejante con una bebida o comida ordinaria) no parece idiomática en ático clásico, el cual repetidamente muestra el uso con ac. (cf. X., An. V 8.20, I 5.6, II 1.6, Pl., Tht. 159c, Pl., Smp. 176c, 223 b, Prt. 347e, Ar., Plu. 645, Pax 852, Ra. 1150, Plu. 1085, Arist., HA 597 29, $614^{\mathrm{b}} 30$, Po. $1461^{\mathrm{a} 30}$, etc. como ya en Hom., Od. X 460, Hes., Op. 147). Justo al contrario de lo que parecen opinar unánimemente las gramáticas del Nuevo Testamento, es el griego tardío (helenístico, koiné y aticista) el que muestra cierta tendencia a usar la expresión partitiva, aunque algunos regis-

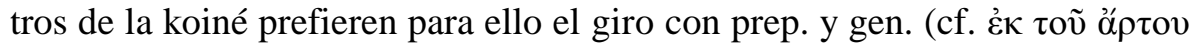

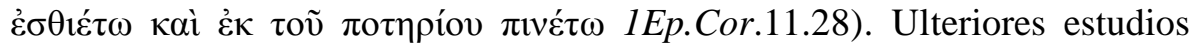
serán necesarios para delimitar el uso de la construcción de los verbos "comer", "beber" en gen., en la prosa aticista y de la koiné, que necesariamente deberán tener en cuenta la influencia del latín en ciertos autores (como Aelianus). El uso en otras lenguas (y por tanto otros sistemas de casos) exigirán presumiblemente otras explicaciones.

Quisiera hacer una atrevida observación final acerca de los verbos con sujeto necesariamente animal: el hecho de que tales verbos ("pastar", etc.) exijan siempre caso ac. (cuando el sentido no es meramente "rumiar", etc., que indica un actividad atélica) podría ser una consecuencia de que se conceptúan de forma algo distinta de los verbos con sujeto humano A falta de evidencias a favor o en contra, podría sugerir como hipótesis explicativa la siguiente: el hecho de que por definición el sujeto de estos verbos (y por tanto el beneficiario de la acción), nunca sea el hablante, y siempre un objeto de la experiencia, hace que el objeto gramatical de tales verbos conserve siempre el papel observable de objeto transformado.

APÉNDICE. Verbos de "comer", "beber" con un genitivo de otro tipo

A los propósitos de este estudio sobre la marca de caso del primer complemento argumental de los verbos de "comer", "beber", no he contabilizado los siguientes complementos en gen. (o con un sufijo que indica procedencia), por tratarse de construcciones que deben su marca de caso al desempeño de otra función sintáctica semántica, o a tratarse de diferentes concepualizaciones semánticas:

(a) Construcciones c. gen. (y gen. prep.) de origen, que indican el recipiente o con-

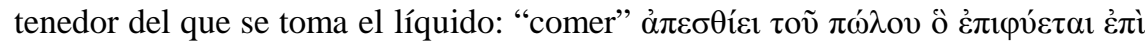

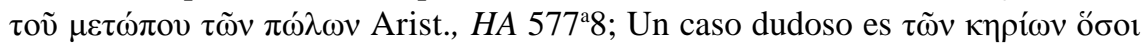

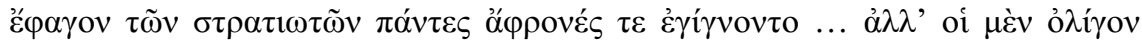




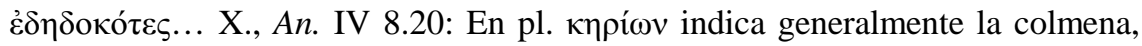
no la miel, pero si se entiende esto último, sería un ejemplo perfecto del grupo

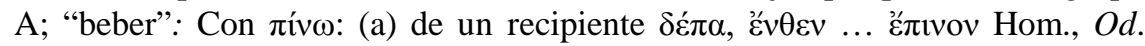
XIX 62, cf. E., Cyc. 530, Arist., SE 178 34 , Thgn.962. (b) de una fuente, río, etc.

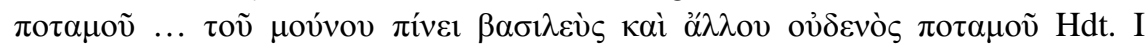
188.1, cf. 1Ep.Cor.10.4, Longus I 20.3, IV 26.4, Ach.Tat. IV 18.3, Plu., Pomp.

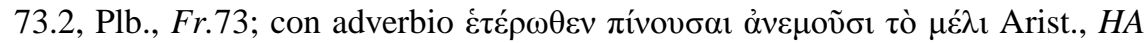

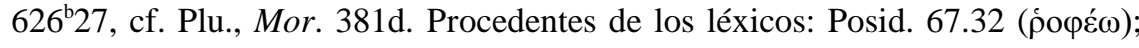

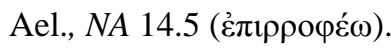

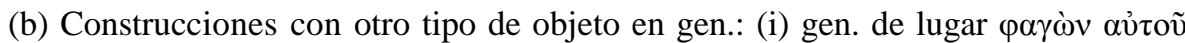

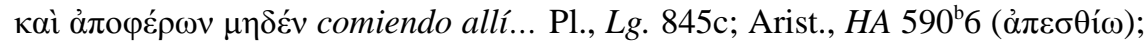

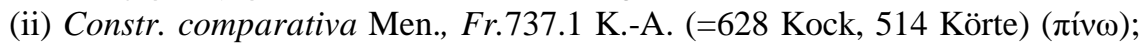

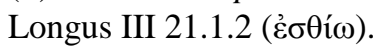

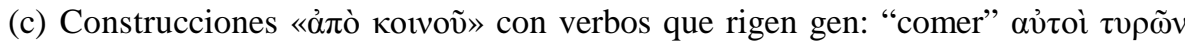

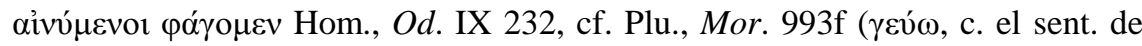
“probar"), Arist., HA 590 b, Fr. 36 (prob. no de Arist.); "beber” Hdt. IV 172.4, Pl., R. 621b.

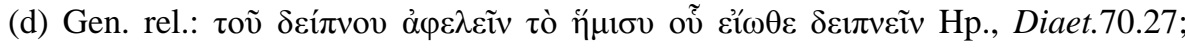
Hdt. IV 2.1 (Con غ̇ $\sigma \theta i ́ \omega ;$ quizás sea un caso particular del G-A: Hdt. parece no haber comprendido la relación entre el trabajo de los esclavos y el hecho de que

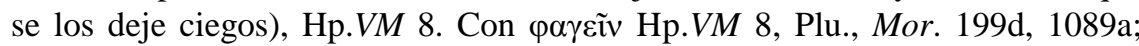

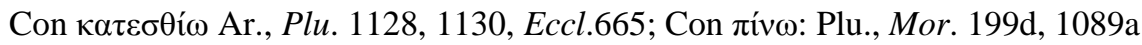
(v. supra).

(e) Textos de autores posteriores al s. II d.C., incluidos en CCB. Las siguientes citas de "comer" cumplen todos los requisitos para incorporarse a nuestro G-A, y sólo las excluimos por la dificultad de atribuirles una fecha aproximada, o por ser citas de otros autores: Arist., Mir. 831 $27,844^{\text {b } 32, ~ 845 ~} 30$, Fr.343.22.

\section{REFERENCIAS}

Basile, Nicola (aut.) y Radici Colace, Paola (Coord.), 1998: Sintassi storica del greco antico. Collana di didattica e manualistica (F. de Martino, ed.), Bari.

Blake, Barry J., 1994: Case. Cambridge Textbooks in linguistics, Cambridge.

Blass, Friedrich; Debrunner, Albert y Funk, Robert W.: 1961, A Greek grammar of the New Testament and other Christian literature. trad. inglesa revisada de la $10^{\mathrm{a}}$ ed. alemana., Chicago.

Chantraine, Pierre, 1953: Grammaire Homérique. Tome II: Syntaxe. 6 reimpr. (1986) París.

EMERITA (EM) LXXIII 2, julio-diciembre $2005 \quad$ pp. 263-302 ISSN 0013-6662 
Delbrück, Berthold, 1893: Vergleichende Syntax der indogermanischen Sprachen. Grundriss der vergleichenden Grammatik der indogermanischen Sprachen (K. Brugmann y B. Delbrück, eds.), Estrasburgo.

Hopper, Paul J. y Thomson, Sandra A., 1980: «Transitivity in grammar and discourse.» Language 56, pp. 251-299.

Humbert, Jean, 1960: Syntaxe Grecque. 3 ed., París.

Kühner, Raphael y Gerth, Bernhard, 1898: Ausführliche Grammatik der griechischen Sprache. 3 ed., Vol. 2, Hannover y Leipzig. = Küh.-G.Gr.Gr.

Lasso de la Vega, José, 1968: Sintaxis griega., Madrid.

Nachmanson, Ernst, 1942: Partitives Subjekt im Griechischen., Göteborg.

Radermacher, Ludwig, 1911: Neutestamentliche Grammatik. Handbuch zum Neuen Testament (W. e. a. Bauer, ed.), Tubinga.

Riemann, Othon y Cucuel, Ch., 1887: Syntaxe Grecque. París.

Riaño Rufilanchas, Daniel 2004: Estudios de sintaxis de los casos casos acusativo, genitivo y dativo en la prosa del griego antiguo. Madrid.

Riaño Rufilanchas, Daniel 2006a: El complemento directo en griego antiguo. Anejos de EMERITA, CSIC, Madrid.

Riaño Rufilanchas, Daniel 2006b: «La marca de caso de los pronombres recíproco y reflexivo en función argumental», en E. Crespo - J. de la Villa - A. Revuelta Puigdollers (eds.), Actas del Coloquio Internacional sobre sintaxis del griego antiguo(CISGA-2003), Lovaina.

Rosén, Hannah, 1986: «One instance of the partitive subject in Literary Latin.» Glotta 64, pp. 84-90.

Schwyzer, Eduard y Debrunner, Albert, 1950: Griechische Grammatik. II: Syntax und syntaktische Stilistik. $5^{\text {a }}$ reimpr. 1988, Múnich.

Turner, Nigel, 1963: A grammar of New Testament Greek. Vol. III: Syntax. Edimburgo.

Con arreglo a las normas editoriales vigentes para las publicaciones periódicas del CSIC, se hace constar que el original de este artículo se recibió en la redacción de EMERITA en el segundo semestre de 2004, siendo aprobada su publicación en ese mismo período.

EMERITA (EM) LXXIII 2, julio-diciembre 2005 pp. 263-302 ISSN 0013-6662 